University of Wollongong

Research Online

Faculty of Engineering and Information

Faculty of Engineering and Information

Sciences - Papers: Part B

Sciences

2019

Improved Performance of Ballasted Tracks under Impact Loading by

Recycled Rubber Mats

Ngoc Trung Ngo

University of Wollongong, trung@uow.edu.au

Buddhima Indraratna

University of Wollongong, indra@uow.edu.au

Cholachat Rujikiatkamjorn

University of Wollongong, cholacha@uow.edu.au

Follow this and additional works at: https://ro.uow.edu.au/eispapers1

Part of the Engineering Commons, and the Science and Technology Studies Commons

Research Online is the open access institutional repository for the University of Wollongong. For further information contact the UOW Library: research-pubs@uow.edu.au 


\title{
Improved Performance of Ballasted Tracks under Impact Loading by Recycled Rubber Mats
}

\author{
Abstract \\ Ballasted tracks at transition locations such as approaches to bridges and road crossings experience \\ increasing degradation and deformation due to dynamic and high impact forces, a key factor that \\ decreases the stability and longevity of railroads. One solution to minimise ballast degradation at the \\ transition zones is using rubber energy absorbing drainage sheets (READS) manufactured from recycled \\ tyres. When placed beneath the ballast layer, READS distributes the load over wider area and attenuate of \\ the load over a longer duration thus decreasing maximum stress, apart from reducing the energy \\ transferred to the ballast and other substructure components. Subsequently, the track substructure \\ experiences less plastic deformation and degradation. These mats also provide an environmentally \\ friendly and cost-effective alternative. In this study, a series of large-scale drop hammer impact tests was \\ carried out to investigate how effectively the READS could attenuate impact loads and help mitigate \\ ballast deformation and degradation. Soft and stiff subgrade were used to investigate the load- \\ deformation response of ballast (with and without READS), subjected to impact loads from a hammer \\ dropped from various heights ( $\mathrm{hd}=100-250 \mathrm{~mm}$ ). Laboratory test results show that the inclusion of \\ READS helps to reduce the dynamic impact load transferred to the ballast layer resulting in significantly \\ less permanent deformation and degradation of ballast, apart from significant attenuation of load \\ magnitude and vibration to the underlying subgrade layers.
}

\section{Keywords}

recycled, loading, impact, under, tracks, mats, ballasted, rubber, performance, improved

\section{Disciplines}

Engineering | Science and Technology Studies

\section{Publication Details}

Ngo, T. Ngoc ., Indraratna, B. \& Rujikiatkamjorn, C. (2019). Improved Performance of Ballasted Tracks under Impact Loading by Recycled Rubber Mats. Transportation Geotechnics, 20 100239-1-100239-16. 


\section{Improved Performance of Ballasted Tracks under Impact Loading} by Recycled Rubber Mats

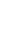

(1)
Training Centre for Advanced Technologies in Rail Track Infrastructure (ITTC-Rail), University of Wollongong Australia, Wollongong, NSW 2522, Australia.
Research Fellow, Centre for Geomechanics and Railway Engineering (CGRE) and ARC

\author{
Trung Ngoc Ngo, PhD, MIEAust.
}

Buddhima Indraratna, PhD (Alberta), FIEAust., FTSE, FASCE

Distinguished Professor of Civil Engineering, Research Director, Centre for Geomechanics and Railway Engineering (CGRE) and ARC Training Centre for Advanced Technologies in Rail Track Infrastructure (ITTC-Rail), University of Wollongong Australia, Wollongong, NSW 2522, Australia.

Cholachat Rujikiatkamjorn, PhD, FIEAust.

Associate Professor, Centre for Geomechanics and Railway Engineering (CGRE) and ARC

Training Centre for Advanced Technologies in Rail Track Infrastructure (ITTC-Rail), University of Wollongong Australia, Wollongong, NSW 2522, Australia.

\title{
Technical paper submitted to: Transportation Geotechnics
}




\section{Improved Performance of Ballasted Tracks under Impact Loading by Recycled Rubber Mats}

Trung Ngoc Ngo ${ }^{1}$ MIEAust, Buddhima Indraratna ${ }^{2}$ F.ASCE and Cholachat Rujikiatkamjorn ${ }^{3}$

${ }^{1}$ Research Fellow, Centre for Geomechanics and Railway Engineering (CGRE), ARC Training Centre for Advanced Technologies in Rail Track Infrastructure (ITTC-Rail), University of Wollongong Australia, Wollongong, NSW 2522, Australia. Email: trung@uow.edu.au, Ph: +61 242213385 Fax: +61 242213238

${ }^{2}$ Distinguished Professor of Civil Engineering, Research Director, Centre for Geomechanics and Railway Engineering (CGRE), ARC Training Centre for Advanced Technologies in Rail Track Infrastructure (ITTC-Rail), University of Wollongong Australia, Wollongong, NSW 2522, Australia.

Email: indra@uow.edu.au, Ph: +6124221 3046 Fax: +61 242213238

\footnotetext{
${ }^{3}$ Associate Professor, Centre for Geomechanics and Railway Engineering (CGRE), ARC Training Centre for Advanced Technologies in Rail Track Infrastructure (ITTC-Rail), University of Wollongong Australia, Wollongong, NSW 2522, Australia. Email: cholacha@uow.edu.au, Ph: +61 242215852 Fax: +61 242213238
}

ABSTRACT: Ballasted tracks at transition locations such as approaches to bridges and road crossings experience increasing degradation and deformation due to dynamic and high impact forces, a key factor that decreases the stability and longevity of railroads. One solution to minimise ballast degradation at the transition zones is using rubber energy absorbing drainage sheets (READS) manufactured from recycled tyres. When placed beneath the ballast layer, READS distributes the load over wider area and attenuate of the load over a longer duration thus decreasing maximum stress, apart from reducing the energy transferred to the ballast and other substructure components. Subsequently, the track substructure experiences less plastic deformation and degradation. These mats also provide an environmentally friendly and cost-effective alternative. In this study, a series of large-scale drop hammer impact tests was carried out to investigate how effectively the READS could attenuate impact loads and help mitigate ballast deformation and degradation. Soft and stiff subgrade were used to investigate the load-deformation response of ballast (with and without READS), subjected to impact loads from a hammer dropped from various heights $\left(h_{d}=100-250 \mathrm{~mm}\right)$. Laboratory test results show that the inclusion of READS helps to reduce the dynamic impact load transferred to the ballast layer resulting in significantly less permanent deformation and degradation of ballast, apart from significant attenuation of load magnitude and vibration to the underlying subgrade layers.

Keywords: Ballast, Rail transport, Recycled rubber mats, Impact loading, Particle breakage, Load attenuation, Stress transfer 


\section{Introduction}

71 Ballasted rail tracks are the major infrastructure for freight and passenger transport in Australia;

72 this rail network is more than $40,000 \mathrm{~km}$ long and provides a vital supply chain to the agriculture

73 and mining industries (Indraratna et al. 2011a). Australian rail infrastructure is often constructed

74 on coastal subgrade soils that can lead to excessive settlements and unstable track conditions. In

75 recent years traditional railway foundations have become overloaded due to increasing demand for

76 faster and heavier trains. This demand is accelerating the deterioration of track substructure while 77 increasing the maintenance costs (Selig and Waters 1994, Tutumluer et al. 2012, Indraratna et al

78 2014, Boler et al. 2018). During operation, rail vehicles generate noise, vibration, and impact loads

79 due to roughness and imperfections at the wheel-rail interface. Impact loads are commonly

80 generated by: (i) differential stiffness at track transition zones such as bridge approaches, rail

81 crossings, and turnouts; and (ii) rail abnormalities such as wheel flats and dipped rails which

82 seriously hamper the safety and efficiency of tracks (Varandas et al. 2011, Insa et al. 2014). It is

83 also noted that track transitions such as bridge approaches, road crossings and slab tracks in

84 connection with ballasted tracks are common locations of accelerated track degradation due to

85 abrupt changes in support stiffness, and associated differential settlements. Differential settlement

86 contributes to gaps forming just beneath sleepers, hence the effective support stiffness can decrease

87 greatly as felt by carriages.

88 During passage of trains, ballast aggregates spread laterally mainly due to inadequate confining 89 pressure and they deteriorate as angular corners and sharp edges break (Indraratna et al. 2016, 90 Powrie et al. 2007, Sayeed and Shahin 2016, Le Pen and Powrie 2011). Consequently, ballast 91 becomes fouled, less angular and has reduced shear strength, which leads to enforced speed

92 restrictions and more frequent track maintenance. A large proportion of track maintenance costs is

93 related to issues with track substructure such as ballast degradation, fouling, poor drainage (mud94 pumping), differential settlement, and track buckling (Tennakoon et al. 2012, Navaratnarajah et 95 al. 2018, Ngo et al. 2017a). In NSW alone, replenishing ballast costs over \$15 million per year 96 and it has a detrimental impact on the landscape and environment. In the USA the annual cost of 97 maintenance for ballast tamping and surface alignment is approximately \$3,800 per kilometre 98 (Chrismer and Davis 2000). Hence, there is a definite need for innovative design solutions that can 99 minimise ballast degradation and extend the service life of tracks to cater for faster and heavier 100 trains. 
101 Previous studies showed that planar polymeric geogrids could improve track stability and facilitate 102 track drainage through the interaction between ballast particles and apertures (Bathurst and 103 Raymond 1987, Kwon and Penman 2009, Indraratna et al. 2011b). The ability of geogrid 104 reinforcement to provide lateral constraint to ballast has been discussed by McDowell et al. (2006), 105 Shukla and Yin (2006), Ngo et al. (2016). The effect of placing geogrid under ballast lying on stiff 106 foundation (e.g. under concrete bridge decks or level crossings) or at transition zones may be 107 limited because it may not adequately absorb the predominant impact loads (Nimbalkar and 108 Indraratna 2016, Ngo et al. 2017b). In fact despite the use of geogrid, significant ballast 109 degradation has been observed and measured in the field by Indraratna et al. (2014).

110 The use of resilient rubber mats in rail tracks to reduce noise and vibration has become increasingly 111 common (e.g. Auersch 2006, Hanson and Singleton 2006, Wettschureck 1997). Rubber mats have 112 recently been trialled for track substructure under stiff foundations to minimise permanent 113 deformation and degradation of aggregates, while enhancing the overall track stability (Costa et 114 al. 2012, Lakuši et al. 2010, Finegan and Gibson 1999). These studies found that the rubber mats 115 could provide better load transfer at the interface between ballast aggregates and stiff foundation 116 by increasing the contact area, reducing the contact forces, thus minimising track damage.

117 Most of these previous studies have been conducted either in controlled laboratory or field trial 118 tests subjected to limited loading and boundary conditions; a few attempts have been made to study 119 the effects of rubber mats under high dynamic impact loads. Given that installing rubber mats in 120 rail tracks helps to absorb energy, attenuates impact loads and reduces track vibration, the actual 121 interaction mechanisms between the ballast and rubber mats are complex, depending on the type 122 of inclusions, the nature of the subgrade, and the stress state in the track environment. Moreover, 123 studies on the performance of rubber mats under different subgrade conditions while being 124 subjected to varying magnitudes of impact loads are limited. Müller (2008) confirmed that when 125 rubber mats were installed in stiff foundations, they performed differently than when placed on 126 soft subgrade.

127 This paper presents a study on how READS influence in mitigating ballast breakage and reducing 128 ballast deformation by conducting a series of large-scale impact tests on ballast. The idea of the 129 testing program in this study was to demonstrate how the rubber mats can be effectively used to 130 decrease the deformation and degradation (breakage) of ballast under impact loads. To the authors’ 
131 knowledge, the mechanism of improvement of a recycled rubber mat when placed underneath the

132 ballast is a combination of: (i) attenuation of the load over a longer duration thus reducing the 133 peak; (ii) distributing the load over wider area thus decreasing the maximum stress; and (iii) the 134 absorption of the energy imparted by impact loads that could then reduce the amount of energy 135 transferred to the ballast layer.

\section{Experimental study}

\section{2.1. Drop weight impact testing facility}

139 A high-capacity drop weight impact testing equipment was used to evaluate the ability of READS to attenuate dynamic impact loads and mitigate ballast degradation (Figure 1a). The impact 141 apparatus consists of a $5.81 \mathrm{kN}$ free fall hammer that can be dropped from a maximum height of $1426 \mathrm{~m}$, with an equivalent maximum drop velocity of $10 \mathrm{~m} / \mathrm{s}$ (Remennikov and Kaewunruen 2010). 143 The hammer is attached to rollers that are guided through low-friction runners on vertical steel 144 columns fixed onto a reinforced concrete floor. A schematic diagram of a typical ballast sample 145 tested in the laboratory is shown in Figure 1b. It is noted that the thickness of subgrade can 146 influence the test results. Given the fixed dimensions of the steel mould and the surrounding cell 147 membrane (approx. $600 \mathrm{~mm}$ height), the thickness of ballast and capping layers have been 148 maintained to be 350 and $100 \mathrm{~mm}$, respectively, to represent typical Australian track conditions, 149 and also a 50mm thick subgrade layer was placed within the depth limitation of the test chamber.

150 A piezoelectric accelerometer was attached to the top surface of the sample assembly to measure 151 acceleration. The accelerometer was positioned at a distance of $42 \mathrm{~mm}$ away from the center of 152 the specimen, as shown in Figure 1b. A dynamic load cell was attached to the hammer to record 153 the impact loads during testing, and a high speed camera (recording at 500 frames per second) was 154 used to record the deformation during testing (Figure 1c). These instruments were connected to a 155 host computer controlled data acquisition system (Figure 1d). The drop hammer was hoisted 156 mechanically to the required height and was released by an electronic control system. During the 157 tests, the impact load and acceleration were recorded digitally and filtered using a low-pass fourth158 order Butterworth filter with a cut-off frequency of 2,000 Hz. 
It is worth mentioning that typical Australian heavy haul and freight trains can have a length of up to $5 \mathrm{~km}$ long. These trains will generate multiple repeated impact loads due to roughness and imperfections at the wheel-rail interface or when they pass through transition zones such as bridge approaches, rail crossings, etc. In the absence of appropriate laboratory facilities to simulate actual impact of a very long train running on ballast track, the repeated hammer dropping test (impact testing facility) is considered as an appropriate test to characterize ballast performance with different track substructure components (soft and stiff subgrade). The impact testing facility was designed and built at the University of Wollongong Australia, has been widely used to test railway concrete sleepers by Remennikov and Kaewunruen (2010) subjected to high impact loading, and routinely used by railway asset owners in the state of NSW for testing track elements.

\subsection{Materials tested}

All tests were conducted on a simulated track substructure lying on: (a) soft subgrade, and (b) stiff subgrade (reinforced concrete base) to represent a bridge. Ballast aggregates taken from Bombo quarry near Wollongong city is latite basalt, an igneous rock form commonly found along the south coast of New South Wales, Australia. These dark aggregates have a high compressive strength and sharp angular corners when blasted and quarried. Uniaxial compressive strength of parent rock used for ballast aggregates is approximately, $\sigma_{c}=130 \mathrm{MPa}$. The ballast has been sieved, cleaned, weighed, and mixed according to the current Australian practices (AS:2758.7, 2015), shown in Figure 2. A $50 \mathrm{~mm}$ thick layer of sandy-clay soil, compacted at 7\% moisture content to a bulk unit weight of $18.5 \mathrm{kN} / \mathrm{m}^{3}$, was placed at the bottom of the apparatus, and then a $100 \mathrm{~mm}$ thick layer of capping (sub-ballast) consisting of a sand and gravel mixture (Figure 3a) compacted to a bulk unit weight of $20.5 \mathrm{kN} / \mathrm{m}^{3}$ was placed on top of the subgrade layer. The capping layer was replaced by a reinforced concrete base to simulate a stiff foundation (i.e. crossings or concrete bridge decks). A recycled rubber mat, manufactured from a recycling company in Australia, was placed on top of the capping layer (Figure 3b), followed by a $350 \mathrm{~mm}$ thick layer of ballast. Total weight of ballast (38.3 kg) was used for each test and was divided and compacted into 3 equal sub-layers (i.e. $115 \mathrm{~mm}$ thick). The ballast aggregates in each sub-layer were painted in different colours to help assess the amount of degradation each layer experiences during the tests, i.e. yellow for the bottom layer, no colour for the middle layer, and red for the top layer (Figure 3c-d). A rubber pad 
189 was attached to the vibrator to prevent particle breakage during tamping. A recycled energy 190 absorbing drainage mat (READS) contain very small perforations to facilitate drainage and to 191 prevent build-up of interface water pressures. These perforations also act as 'frictional' elements 192 maintaining good contact with the granular layer on either side (ballast and sub-ballast). 193 Essentially, this mat is permeable and it has a permeability coefficient approximately of $2.5 \times 10^{-4}$ $194 \mathrm{~cm} / \mathrm{sec}$. It is worth mentioning that upon repeated train loading, fine particles may accumulate on 195 the surface of the mat, and as a result the permeability may be decreased, as observed in a field 196 trial in Singleton (Indraratna et al. 2014). The mechanical properties of the READS used in the 197 laboratory are presented in Table 1.

198 Dynamic impact loads are commonly caused by wheel or rail abnormalities such as flat wheels, 199 dipped rails, expansion gaps between two rail segments, imperfect rail welds and rail corrugations, 200 and transition zones (Esveld 2001, LePen 2008, Priest et al. 2010). The flange-way gap that 201 provides clearance between the wheel flange and the point where rails intersect is also responsible 202 for the development of large impact loads (Anastasopoulos et al. 2009). When a train passes 203 through a rail crossing and through turnouts or transition zones, the rapid change in wheel rail 204 contacts coupled with sudden variations in track stiffness causes the wheels to displace up and 205 down, giving rise to impact loads (Paixão et al. 2014, Remennikov and Kaewunruen 2014, Powrie 206 et al. 2007). Impacts at turnouts may also occur at the switch points due to the shape and flexibility 207 of the movable blades used to control the direction of train passage (Bruni et al. 2009). At transition 208 points such as bridge approaches, road crossings and slab track to ballasted track, a considerable 209 change in track stiffness causes high impact forces that accelerate track deformation. This issue 210 becomes even more critical for shared lines between faster passenger trains and heavier freight 211 trains.

\section{$212 \quad$ 2.3. Sample preparation and testing program}

213 A $7 \mathrm{~mm}$ thick cylindrical rubber membrane having a 300mm diameter was used to assemble the 214 ballast specimen (Figure 4a). Two halves of a steel mould that surrounds the cell membrane (Figure 215 4b) were used to support the sample during the compaction. The capping material (sub-ballast) 216 was also weighed, sieved, and compacted to a thickness of $100 \mathrm{~mm}$ following the particle size 217 distribution described in Figure 2. A layer of recycled rubber mat (READS -10mm thick) was 218 placed above the capping layer. 
219 The first layer of ballast was placed directly onto the READS and was compacted using a hand220 held vibrating hammer to attain a unit weight of $15.5 \mathrm{kN} / \mathrm{m}^{3}$. This process was repeated for the 221 next two layers of ballast (Figure 4c), and then a steel plate (loading plate) was fitted at the top of 222 the ballast and fastened by steel ties. The initial height of specimen was measured and recorded at 223 four evenly spaced points around the cell. The circumference of the cell was measured at three 224 locations (i.e. bottom layer, middle layer, and the top layer of ballast). These initial measurements 225 serve as references for determining the vertical and lateral deformation of the ballast assembly as 226 the tests progress. It is noted that the use of a membrane to confine ballast does not perfectly 227 represent the actual field conditions where the aggregates displace laterally under limited lateral 228 confinement provided by sleepers and ballast shoulders (Indraratna et al. 2011a). A $7 \mathrm{~mm}$ thick 229 cylindrical rubber membrane could include some boundary effects to the ballast grains near the 230 walls and may affect the reflection of waves at the boundary, and this boundary influence is a 231 limitation of the equipment. A rigid boundary with low friction (i.e. cylindrical steel tube) was 232 also tried but it generated a large impulse shock and the ballast assembly vibrated significantly 233 when the hammer dropped onto to the sample, hence not suitable for assembling ballast specimens. 234 Therefore, the use of a $7 \mathrm{~mm}$ thick cylindrical rubber membrane is the most suitable for the impact 235 test and the boundary condition have been maintained constantly for all the tests. An additional 236 confining stress induced on the ballast specimen by the membrane $\left(\Delta \sigma_{3}\right)$ at a given number for 237 hammer drops can be estimated and described in Appendix 1.

238 A total of 16 tests were conducted on ballast with and without the inclusion of READS placed on 239 a soft subgrade (Young's modulus of elasticity of subgrade, $E_{s u}=55 \mathrm{MPa}$ ) and a stiff base 240 (concrete) subjected to varying impact loads (i.e. varying drop heights of the hammer as: $h_{d}=100$ $241 \mathrm{~mm}, 150 \mathrm{~mm}, 200 \mathrm{~mm}$ and 250mm), as shown in Figure 4e. These drop heights produce equivalent 242 dynamic stresses between $250-550 \mathrm{kPa}$, simulating typical impact forces caused by wheel flats and 243 dipped rail joints in the field (Jenkins, et al. 1974, Esveld 2001, Indraratna et al. 2011a). A 244 previously made reinforced cylindrical concrete base $(300 \mathrm{~mm}$ in diameter and $100 \mathrm{~mm}$ in 245 thickness) was used as the stiff base, which was placed directly on the subgrade layer. The impact 246 test program is summarised in Table 2. Every test was subjected to 15 drops; after each drop the 247 vertical and lateral displacements of the ballast specimen were measured (Figure 4f). After each 248 test, ballast aggregates in each layer were separately sieved to quantify the amount of breakage. 


\section{Results and Discussion}

250 3.1. Measured vertical displacement

251 Figure 5 shows typical images captured by the high speed camera of deformed ballast assemblies, 252 recorded before and after the $10^{\text {th }}$ drop (drop height, $h_{d}=150 \mathrm{~mm}$ ). When a hammer was dropped 253 on the top loading plate, it began to compress the ballast specimen (Figure 5a). The sample was 254 compressed to its maximum vertical displacement at time $t=15 \mathrm{~ms}$ (Figure $5 \mathrm{~b}$ ), and then the 255 ballast assembly rebounded upwards to a residual position (Figure 5c). Upon impact loading, 256 elastic settlement occurs, followed by plastic vertical displacement. Typical time-settlement 257 responses of ballast assemblies measured at different drops placed on the concrete base, subjected 258 to a drop height of $h_{d}=150 \mathrm{~mm}$ are shown in Figure 6. It is seen that the ballast assemblies deform 259 from their original position to a maximum displacement and then return to a residual (permanent) 260 settlement in about 120 ms. The inclusion of READS at the interface of the ballast/capping layer 261 resulted in decreased deformation of ballast. The maximum vertical displacement after the $15^{\text {th }}$ 262 drop, with and without the inclusion of READS, is $77.05 \mathrm{~mm}$ and $84.76 \mathrm{~mm}$, respectively, and the 263 corresponding residual settlement is $64.50 \mathrm{~mm}$ and $74.20 \mathrm{~mm}$. It is noted that the presence of the 264 mat increases the elastic range of movement before plastic deformation of the ballast can take 265 place, and moreover by attenuating the peaks in the loading to reduce the plastic deformation 266 (Figure 6). The presence of a rubber layer beneath the ballast layer is also helpful for stabilising 267 the ballast contacts and improving the homogeneity of stress transfer.

268 Variation of the peak and residual vertical displacements of a ballast assembly placed on stiff 269 subgrade and subjected to a given drop height of $h_{d}=150 \mathrm{~mm}$ is plotted in Figure 7. As expected, 270 the vertical displacement of the ballast specimen without READS is higher than the READS271 reinforced ballast assembly. The laboratory test data show that ballast deformation increases with 272 an increase in number of hammer drops due to the reorientation, rearrangement, and corner 273 breakage of aggregates. Towards the end of testing, the deformation of ballast occurs at a 274 diminishing rate.

275 Figure 8 shows the variations of the accumulated permanent vertical settlement of ballast 276 assemblies with and without READS placed on both soft and stiff subgrade. As expected, 277 settlement generally increases as the drop height, $h_{d}$ increases. There is a distinct trend of 278 increasing vertical settlement within the first ten impact drops followed by a gradual increase of 
279 vertical displacement at a decreasing rate. After attaining a threshold compression after the $10^{\text {th }}$ 280 drop, the ballast resists further settlement, but promotes particle breakage.

281 3.2. Measured lateral deformation

282 Under an impact load, ballast aggregates are compressed and displaced laterally. After each 283 hammer drop, the circumference of ballast specimens was measured at the top, middle, and bottom 284 of the ballast layers (locations: A, B, C in Figure 5a). The average accumulative lateral 285 displacements, $S_{h}$ for each test are shown in Figure 9. Measured data indicate that in every case 286 the lateral deformation increases with successive impacts, but the rate of increase in lateral 287 deformation gradually reduces after the $10^{\text {th }} \mathrm{drop}$. The initially rapid lateral displacement of ballast 288 could be attributed to the high rate of ballast degradation that takes place at this stage. Indraratna 289 et al. (2013) observed that ballast deformation was mainly due to the breakage of ballast particles 290 and particle re-arrangement. With the inclusion of READS, measured lateral deformation of ballast 291 decreases for both types of subgrade because the energy absorbing capacity of READS ensures 292 less energy to be transferred to ballast aggregates and thereby reduce deformation. It is seen from 293 Figs. 8 and 9 that the recycled rubber mat provides beneficial effects in decreasing the vertical and 294 lateral deformation of ballast assemblies when placed on both soft and stiff (concrete) subgrades. 295 Compared to a stiff subgrade, a weak subgrade itself serves as a flexible cushion to attenuate the 296 impulse waves; hence, the beneficial role of the ballast mat remains under-utilized (i.e. less 297 reduction in ballast deformation). The effect of subgrade stiffness is best interpreted and further 298 discussed based on Figure 12.

\section{3.3. Ballast breakage}

300 Impact loads produce a series of physical phenomena such as elastic shock, plastic wave 301 propagation, fracture and fragmentation that affects the strength and deformation of granular 302 materials (Meyers 1994). After the impact tests, different types of particle degradation were 303 observed such as grinding (abrasion), angular corner breakage (due to attrition), and distinct 304 splitting across the body of particles (fracture). The ballast breakage index ( $B B I$ ) was first 305 introduced by Indraratna et al. (2005) based on the particle size distribution (PSD) curves, and it 306 has been widely used to quantify ballast breakage. The $B B I$ is determined on the basis of change 307 in the fraction passing a range of sieves, where the amount of ballast breakage causes the PSD 308 curve to shift further towards the smaller particles size region on a conventional PSD plot, as 
described in Figure 10. The $B B I$ is given by the relationship: $B B I=A /(A+B)$, where, $A$ is shift in 310 the PSD curve after the load application and $B$ is potential breakage or the area between the 311 arbitrary boundary of maximum breakage and the final PSD curve. The BBI with and without the 312 inclusion of READS placed on the soft and stiff subgrade, subjected to varying drop heights $\left(h_{d}=\right.$ 313 100-250 mm) are plotted in Figure 11. As expected, the maximum ballast breakage occurs in the 314 top layer, and it decreases in the middle and bottom layers as the induced impact loads attenuate 315 with depth. Figure 11 shows a large increase in ballast breakage when the drop height of the 316 hammer increases (increased impact energy); this agrees with the findings of a previous study 317 using a large-scale triaxial apparatus where ballast breakage was observed to increase with an 318 increase in cyclic loads (Sun et al. 2018).

319 The highest value of $B B I=0.352$ was obtained for test CN250 where ballast was placed on stiff 320 subgrade (without READS), and the lowest breakage $(B B I=0.077$ ) was measured for the test 321 SY100 (placed on soft subgrade with READS). When placed on stiff subgrade, it was observed 322 that ballast at the bottom layer still experienced considerable breakage, unlike the ballast in the 323 middle layer which experienced the least (Figure 11c). This is possibly because the ballast 324 aggregates at the bottom layer are restrained against downward movement by the rigid concrete 325 base, whereas the aggregates in the middle layer are relatively free to displace and rotate due to 326 the underlying flexible ballast layer.

327 The measured data is best interpreted by Figure 12, which plots the final values of ballast 328 deformation (Figure 12a-d), the percentage reduction of ballast breakage $\left(R_{b}\right)$, and the relative 329 deformation factors $\left(R_{v}, R_{h}\right)$ with varying drop heights (Figure 12e-f). The relative deformation 330 factors for vertical $\left(R_{v}\right)$ and horizontal displacement $\left(R_{h}\right)$ are defined as follows:

331 Vertical settlement (\%): $\quad R_{v}=\frac{S_{v(\text { No READS })}-S_{v(\text { With READS })}}{S_{v(\text { No } R E A D S)}} \times 100$

332 Lateral deformation (\%): $\quad R_{h}=\frac{S_{h(\text { No READS })}-S_{h(\text { With READS })}}{S_{h(\text { No READS })}} \times 100$

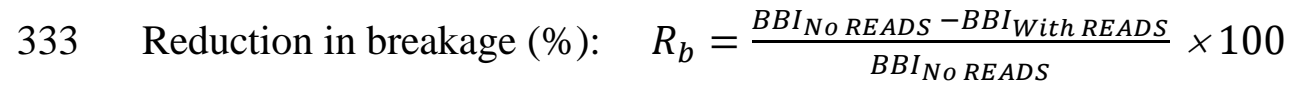

334 It is seen that the vertical and lateral deformations with READS are less than those without READS 335 for a given drop height. The beneficial effects of READS are more pronounced on the stiff 
subgrade, and this corroborates with the energy absorbing nature of READS whereby less energy

337 is transferred to the ballast and other substructure components, thus reduced deformation and degradation. The effect of READS is reflected by reduction factors presented in Figure 12e-f. It is seen that READS could decrease the deformation of ballast around 7-15\% for a given drop height. The reduction in breakage, $R_{b}$ was measured up to $28 \%$ (stiff subgrade) while $R_{b}$ fluctuated around 10 to $17 \%$ for the soft subgrade (average for three layers).

\subsection{Measured impact forces}

343 Figure 13 shows the impact forces measured with and without READS placed on soft subgrade 344 and subject to varied drop heights, $h_{d}=100-250 \mathrm{~mm}$. Data was recorded during the first 200 milliseconds (ms) and was measured at the $10^{\text {th }}$ drop $(N=10)$. Subject to a free-fall hammer, multiple $P_{1}$ type peaks occur followed by the distinct $\mathrm{P}_{2}$ type peak. It is noted that all tests have a similar response pattern with multiple peak forces $\left(P_{1}\right)$ followed by another peak of smaller magnitude (the so-called $P_{2}$ force). An instantaneous sharp peak with very high frequency known as $P_{1}$, and a gradual peak of smaller magnitude and with a relatively lesser frequency, known as $P_{2}$. The impact force $P_{1}$ comes from the inertia of the rail and sleepers that resist the downward motion of the wheel, and this leads to compression in the contact zone between the wheel and the rail. The force $P_{2}$ prevails over a longer duration and is attributed to the mechanical resistance of the track substructure leading to significant compression. $P_{2}$ directly causes ballast breakage and

354 it can be estimated based on the mathematical model proposed by Jenkins et al. (1974):

$355 \quad P_{2}=P_{0}+2 \alpha V \times\left[\frac{M_{u}}{M_{u}+M_{t}}\right]^{0.5} \times\left[1-\frac{C_{t} \pi}{4\left[K_{t}\left(M_{u}+M_{t}\right)\right]^{0.5}}\right] \times\left[K_{t} M_{u}\right]^{0.5}$

where, $P_{0}$ : static wheel load $(\mathrm{kN}) ; M_{u}$ : vehicle unsprung mass $(\mathrm{kg}) ; 2 \alpha$ is the total joint dip angle (rad); $V$ : train speed $(\mathrm{m} / \mathrm{s}) ; K_{t}$ : equivalent track stiffness $(\mathrm{MN} / \mathrm{m}) ; C_{t}$ : equivalent track damping $(\mathrm{kNs} / \mathrm{m})$; and $M_{t}$ : is the equivalent track mass $(\mathrm{kg})$.

The first peak has a sharp triangular shape and a high amplitude between $160 \mathrm{kN}$ to $375 \mathrm{kN}$ for $h_{d}$ $360=100-250 \mathrm{~mm}$ within relatively short time duration (about $15 \mathrm{~ms}$ ). The second peak was measured 361 approximately $20 \mathrm{~ms}$ after the first peak, followed by several local triangular shaped peaks of 362 around $40 \mathrm{kN}$ (about $100 \mathrm{~ms}$ from the first peak). Remennikov and Kaewunruen (2010) found that 363 the inertial force peak induces the specimen to vibrate during the first $15 \mathrm{~ms}$. Any further vibration 364 could separate the hammer and the ballast specimen, as shown by a sharp reduction in the impact 
365 force to almost zero for a short period of $10-30 \mathrm{~ms}$ (after the first $P_{1}$ force). The deformation of 366 the ballast assembly continues to rapidly absorb the additional kinetic energy of the impactor but 367 with smaller impact forces. This process repeated itself several times until the impact load 368 remained at a stable value of around $40 \mathrm{kN}\left(P_{2}\right.$ force).

369 Figure 14 illustrates the overlaying plot of impact forces onto the plot of measured vertical displacements to identify where along the displacement plot in each scenario the peak $P_{1}$ force occurs for a soft subgrade soil for $h_{d}=100 \mathrm{~mm}$. It is seen that the $P_{1}$ occurs within the first $40 \mathrm{~ms}$ 372 during the impact where a significant elastic deformation of ballast occurs. Figure 15 shows 373 comparison of the maximum impact forces $P_{1}$ and $P_{2}$ after the $15^{\text {th }}$ drop for soft and stiff subgrades.

374 The magnitude of impact force $P_{1}$ varies from $154 \mathrm{kN}$ to $500 \mathrm{kN}$ with a short duration of 1 to 15 $375 \mathrm{~ms}$, while the $P_{2}$ forces vary from $32 \mathrm{kN}$ to $98 \mathrm{kN}$. Ballast on stiff subgrade experiences higher 376 maximum impact forces $P_{1}, P_{2}$ than ballast on the soft subgrade; this results in a higher 377 deformation as shown in Figure 12. The inclusion of READS substantially reduces the magnitude 378 of the $P_{1}$ and $P_{2}$ impact force.

3.5. Measured acceleration responses

Typical acceleration of ballast under soft and stiff subgrade (with and without READS) measured at the $10^{\text {th }}$ drop $(N=10)$ subjected to a drop height of $h_{d}=100 \mathrm{~mm}$ is shown in Figure 16. It is noteworthy that the inclusion of recycled rubber mats reduces the peak acceleration and helps to attenuate vibration faster for soft and stiff subgrades. There are several peaks that corroborate with $P_{1}$ force, as shown in the impact force-time plots, and the acceleration becomes negligible after $100 \mathrm{~ms}$. When the hammer first hits the specimen the maximum force $P_{1}$ is observed. With soft subgrade, maximum accelerations are around $66 \mathrm{~g}$ and $105 \mathrm{~g}$ for the ballast assembly with and without READS, respectively. The accelerations measured approximately $110 \mathrm{~g}$ (with READS) and $169 \mathrm{~g}$ (without READS) for stiff subgrade. When the $P_{2}$ force is reached, the mean acceleration is measured around $12 \mathrm{~g}$ and $20 \mathrm{~g}$ for soft and stiff subgrade, respectively. Also, the inclusion of READS helps to attenuate vibration faster, as shown in Figure 16b.

391 Measured accelerations for stiff subgrade are always larger than those for the soft subgrade, which 392 indicates higher levels of vibration at the sleeper-ballast interface. In order to provide further 393 quantitative information related to the energy absorbing characteristics of the recycled rubber mat 394 used in this study, the estimation of energy absorption of the mats based on the strain energy 
concept (i.e. based on the measured deformation of ballast specimen) is described in Appendix 2.

396 It is therefore recommended that the use of READS as a promising approach to be considered for 397 transition zones to reduce vibration and prevent excessive ballast deformation and breakage. This 398 can increase safety and passenger comfort due to vibration attenuation, and lead to a more 399 economical track design due to the subsequent reduction in ballast degradation.

\section{Conclusions}

402 This paper presented the laboratory results from large-scale impact tests to investigate the role that 403 rubber energy absorbing drainage sheet (READS) could provide by reducing deformation and 404 degradation of railway ballast under varied impact loading conditions. From measured test data, 405 the following salient conclusions can be drawn:

- Test data showed that vertical and lateral deformation of ballast increased with the number of impact blows. These observations were more pronounced during the first ten impact drops due to initial densification and further grain packing caused by particle breakage. But once the ballast began to stabilise, the rate of deformation gradually decreased for the subsequent impact drops. The inclusion of READS attenuated both the axial and lateral deformation of ballast, as well as particle degradation under impact loading.

- Two distinct types of force peaks were measured: multiple instantaneous $P_{1}$ peaks followed by a gradual $P_{2}$ peaks of smaller magnitude and longer duration. The magnitude of impact force $P_{1}$ varied from $154 \mathrm{kN}$ to $500 \mathrm{kN}$ with a short duration of around $15 \mathrm{~ms}$, where the $P_{2}$ forces were around $32 \mathrm{kN}$ to $98 \mathrm{kN}$. Note that the maximum values of $P_{1}$ and $P_{2}$ forces increased progressively throughout successive impact blows as the ballast assembly became denser, but these peak values decreased when READS were provided below the ballast layer. READS (energy absorption layer) could reduce the dynamic impact that would have otherwise been transmitted into the ballast and underlying sub-layers. Ballast layer placed on stiff subgrade experienced higher maximum impact forces $P_{1}$ and $P_{2}$ than the one placed on soft subgrade. In addition, laboratory measurements showed that less vibration (acceleration) occurred when READS was installed.

423 The laboratory results obtained in this study provided a better understanding of the capacity of 424 READS to attenuate and distribute the load over wider area, and thus reduce the deformation and 
425 degradation of ballast. In essence, this study presented a quantitative understanding of the extent 426 that the READS could reduce impact-induced forces in ballast while attenuating vibration, as well 427 as substantially reducing ballast breakage.

\section{5. Acknowledgements}

431 This research was conducted by the Australian Research Council Industrial Transformation 432 Training Centre for Advanced Technologies in Rail Track Infrastructure (IC170100006). The 433 authors also greatly appreciate financial support from the Rail Manufacturing Cooperative 434 Research Centre, with subsequent support from organizations including the Australasian Centre 435 for Rail Innovation (ACRI), Tyre Stewardship Australia (Project R2.5.1). The authors thank to 436 graduate student, Timothy Beckmans for their help during laboratory test. The authors appreciate 437 Tim Neville (ARTC) for encouraging the use of recycled rubber mats in real-life tracks. The 438 authors are also grateful to Alan Grant, Cameron Neilson, and Duncan Best for their assistance 439 during the laboratory work. The authors thank Robert Clayton (English editor) for proofreading 440 and professionally editing the manuscript. 
Appendix 1: Estimation of induced lateral confinement provided by the membrane

444 Subjected to impact loads, the membrane deforms laterally. Additional lateral confinement (i.e. 445 induced lateral confinement, $\Delta \sigma_{3}$ ) provided by the membrane can be estimated using the hoop 446 tension theory. Using the Hooke’s law, the circumferential stress $\left(\sigma_{c}\right)$ can be estimated by:

$$
\sigma_{c}=\frac{M_{m}}{\left(1+v_{r}\right) \cdot\left(1-2 v_{r}\right)} \times\left[\left(1-v_{r}\right) \varepsilon_{c}+v_{r}\left(\varepsilon_{3}+\varepsilon_{z}\right)\right]
$$

where, $M_{m}$ is mobilised modulus of the membrane; $\varepsilon_{c}$ and $\varepsilon_{3}$ are circumferential and radial strains, 449 respectively. It is noted that, $\varepsilon_{c}=k . \varepsilon_{3}$; and the ratio, $k$ can be estimated as 0.42 for rubber. $v_{r}$ is 450 the Poisson's ratio of recycled rubber mat $\left(v_{r}=0.44\right)$

451 The loading plate can move downward inside the membrane and $\varepsilon_{z}=0$, and the Eq. (5) can then be 452 simplified to:

$$
\sigma_{c}=\frac{M_{m}}{\left(1+v_{r}\right) \cdot\left(1-2 v_{r}\right)} \times\left[\left(1-v_{r}\right) k \varepsilon_{3}+v_{r} \varepsilon_{3}\right]
$$

454 Due to symmetry of the cylindrical membrane, the lateral confinement applied by the membrane $455\left(\Delta \sigma_{3}\right)$ can be calculated as:

$456 \Delta \sigma_{3}=\frac{2 \sigma_{c}}{D}$

457 where, $D$ is diameter of equivalent circular area of the membrane.

458 Substituting Eq. 6 into Eq. 7, gives:

$459 \Delta \sigma_{3}=\frac{2 M_{m}}{D} \times \frac{\left(1-v_{r}\right) k+v_{r}}{\left(1+v_{r}\right) \cdot\left(1-2 v_{r}\right)} \times \varepsilon_{3}$

460 Based on measured changes in the circumference (i.e. $\varepsilon_{3}$ ) of a ballast specimen (Figure 9), the 461 induced confining stresses onto the ballast specimen by the membrane can then be calculated. 462 Figure 17 presents estimated values of $\Delta \sigma_{3}$ for both soft and stiff subgrade under 2 different drop 463 heights, i.e. $h_{d}=100,200 \mathrm{~mm}$. It is seen that the calculated values of $\Delta \sigma_{3}$ vary from $10-20 \mathrm{kPa}$. It 464 is noted that the ASTM D4767-11 recommends the use of a correction factor for rubber membrane 465 stiffness when determining the deviatoric stress in triaxial testing; for ballast assemblies, the 466 required correction for deviator stress is around 10-15 kPa (Lackenby et al. 2007, Sun et al. 2018). 
Appendix 2: Estimation of energy absorption of the mats

468 As the hammer having a weight of $W$ falls from rest at a given height $h_{d}$, its gravitational potential 469 energy is converted to kinetic energy. Adopting the principle of energy conservation $\left(M g h_{d}=\right.$

$\left.470 \frac{1}{2} M V_{h}^{2}\right)$, the total kinetic energy $\left(E_{K}\right)$ and velocity of hammer when it hits the ballast specimen can 471 be calculated by:

$472 \quad E_{K}=\frac{1}{2} M V_{h}^{2} \quad$ and $\quad V_{h}=\sqrt{2 g h_{d}}$

473

474 The total work done $(W)$ by ballast specimen upon the impact load can then be estimated as:

475

476

- $\quad$ No rubber mat: $W=\frac{1}{2} M V_{h}^{2}=\sigma_{3} \delta V_{0}+\left(\sigma_{1}-\sigma_{3}\right) A \delta s_{0}$

- With rubber mat: $W=\frac{1}{2} M V_{h}^{2}=\sigma_{3} \delta V+\left(\sigma_{1}-\sigma_{3}\right) A \delta s+E_{R M}$

477 where, $\sigma_{1}$ and $\sigma_{3}$ are the major and minor principal stresses, respectively; $\delta V$ is the volume change 478 of the specimen; $\delta s$ is the vertical displacement; $A$ is cross-section area of the ballast sample; $E_{R M}$ 479 is the estimated energy absorbed by the mat, and this can be approximately determined by 480 subtracting Eq.11 from Eq.10.

481 It is noted that for impact tests carried out in this study, $\sigma_{1}$ and $\sigma_{3}$ were not directly measured. For 482 the purpose of simplicity, $\sigma_{1}$ can be estimated from the measured $P_{2}$ forces (i.e. applied over a 483 long duration and causing ballast deformation), and $\sigma_{3}$ is estimated as the applied confining stress 484 by the membrane (i.e. $20 \mathrm{kPa}$ as estimated in Appendix 1).

485 Figure 18 presents the estimated energy absorbing capacity of recycled rubber mat placed on the 486 soft and stiff subgrade after a given number of hammer drops for drop heights of $h_{d}=100,200$ $487 \mathrm{~mm}$. It is seen that the measured $E_{R M}$ of the mat increases with an increase in the number of 488 hammer drops, and the recycled rubber mats perform better when placed on the stiff subgrade. 


\section{References}

491

492

493

494

495

496

497

498

499

500

501

502

503

504

505

506

507

508

509

510

511

512

513

514

515

AS:2758.7: (2015). Aggregates and rock for engineering purposes, Part 7. Railway Ballast. Standard Australia, SAI Global, Australia.

ASTM (2018). Standard test method for consolidated undrained triaxial compression test for cohesive soils, ASTM D4767-11. West Conshohocken, PA: ASTM International.

Anastasopoulos, I., Alfi, S., Gazetas, G., Bruni, S. and Leuven, A.V. (2009). Numerical and experimental assessment of advanced concepts to reduce noise and vibration on urban railway turnouts. Journal of Transportation Engineering, ASCE, 135(5), pp: 279-287.

Auersch, L. (2006). Dynamic axle loads on tracks with and without ballast mats: numerical results of three-dimensional vehicle-track-soil models. Proceedings of the Institution of Mechanical Engineers, 220(F2), pp: 169-183.

Bathurst, R.J. and Raymond, G.P. (1987). Geogrid reinforcement of ballasted track. Transportation Research Record, 1153, pp: 8-14.

Bruni, S., Anastasopoulos, I., Alfi, S., Leuven, V. A., Apostolou, M. And Gazetas, G. (2009). Traininduced vibrations on urban metro and tram turnouts. Journal of Transportation Engineering, ASCE, 135(7), pp.397-405.

Boler, H., Mishra, D., Hou, W. and Tutumluer, E. (2018). Understanding track substructure behavior: Field instrumentation data analysis and development of numerical models. Transportation Geotechnics, 17, pp: 109-121.

Costa, P.A., Calçada, R. and Cardoso, A.S. (2012). Ballast mats for the reduction of railway traffic vibrations. Numerical study. Soil Dynamics and Earthquake Engineering, 42(0), 137-150.

Chrismer, S., and Davis, D. (2000). Cost comparisons of remedial methods to correct track substructure instability. Transportation Research Record: J Transp. Research Board (1713), 10-14.

Esveld, C. (2001). Modern railway track, MRT Press, The Netherlands.

Finegan, I. C., and Gibson, R. F. (1999). Recent research on enhancement of damping in polymer composites. 542 Composite Structures, 44(2-3), 89-98.

Jenkins, H. M., Stephenson, J. E., Clayton, G. A., Moorland, J. W., and Lyon, D. (1974). The effect of track and vehicle parameters on wheel/rail vertical dynamic forces. Railway Engineering Journal, 3(1), 2-16.

Hanson, C.E. and Singleton Jr, H.L. (2006). Performance of ballast mats on passenger railroads: Measurement vs. projections. Journal of Sound and Vibration, 293(3-5), pp: 873-877.

Indraratna, B., Lackenby, J. and Christie, D. (2005). "Effect of confining pressure on the degradation of ballast under cyclic loading." Géotechnique, 55(4), pp: 325-328.

Indraratna, B., Salim, W. and Rujikiatkamjorn, C. (2011a). Advanced Rail Geotechnology Ballasted Track, CRC Press, Taylor \& Francis Group, London, UK

Indraratna, B., Ngo, N.T. and Rujikiatkamjorn, C. (2011b). Behavior of geogrid-reinforced ballast under various levels of fouling. Geotextiles and Geomembranes, 29(3), pp: 313-322. 
Indraratna, B., Ngo, N.T. and Rujikiatkamjorn, C. (2013). Deformation of coal fouled ballast stabilized with geogrid under cyclic load. ASCE-Journal of Geotechnical and Geoenvironmental Engineering, 139(8), pp: 1275-1289.

Indraratna, B., Nimbalkar, S. and Neville, T. (2014). Performance assessment of reinforced ballasted rail track. Proceedings of the ICE - Ground Improvement, 167, pp: 24-34.

Indraratna, B., Nimbalkar, S.S., Ngo, N.T. and Neville, T. (2016). Performance improvement of rail track substructure using artificial inclusions - Experimental and numerical studies. Transportation Geotechnics, 8, pp: 69-85.

Insa, R., Salvador, P., Inarejos, J. and Medina, L. (2014). Analysis of the performance of undersleeper pads in high-speed line transition zones. Proceedings of the Institution of Civil Engineers - Transport, 167(2), pp: 63-77.

Kwon, J. and Penman, J. (2009). The use of biaxial geogrids for enhancing the performance of subballast and ballast layers-previous experience and research. Bearing Capacity of Road, Railways and Airfields Taylor \& Francis Group, London.

Lackenby, J., Indraratna, B., McDowell, G. and Christie, D. (2007). "Effect of confining pressure on ballast degradation and deformation under cyclic triaxial loading." Géotechnique, 57(6), pp: 527-536.

LePen, L. (2008). Track behaviour: the importance of the sleeper to ballast interface. PhD Thesis, University of Southamton, UK.

Le Pen, L.M. and Powrie, W. (2011). Contribution of base, crib, and shoulder ballast to the lateral sliding resistance of railway track: A geotechnical perspective. Proceedings of the Institution of Mechanical Engineers, Part F: Journal of Rail and Rapid Transit, 225(2), pp: 113-128.

Lakuši, S., Ahac, M., Haladin, I. (2010) Experimental investigation of railway track with under sleeper pad. Proceedings of the 10th Slovenian Road and Transportation Congress. pp: 386393.

Remennikov, A.M. and Kaewunruen, S. (2010). Dynamic crack propagation in prestressed concrete sleepers in railway track systems subjected to severe impact loads. ASCE Journal of Structural Engineering, 136 (6), pp. 749-754.

Remennikov, A.M. and Kaewunruen, S. (2014). Experimental load rating of aged railway concrete sleepers. Engineering Structures, 76, pp: 147-162.

McDowell, G.R., Harireche, O., Konietzky, H., Brown, S.F. and Thom, N.H. (2006). Discrete element modelling of geogrid-reinforced aggregates. Proceedings of the ICE - Geotechnical Engineering 159(1), pp: 35-48.

Müller, R. (2008). Mitigation measures for open lines against vibration and ground-borne noise: A Swiss overview. Noise and Vibration Mitigation for Rail Transportation Systems, Springer Berlin Heidelberg, 610 264-270.

Navaratnarajah, S.K., Indraratna, B. and Ngo, N.T. (2018). Influence of under sleeper pads on ballast behavior under cyclic loading: experimental and numerical studies. Journal of Geotechnical and Geoenvironmental Engineering, 144(9), pp: 04018068. 
Ngo, N.T., Indraratna, B. and Rujikiatkamjorn, C. (2016). Modelling geogrid-reinforced railway ballast using the discrete element method. Transportation Geotechnics, 8(2016), pp: 86-102.

Ngo, N.T., Indraratna, B. and Rujikiatkamjorn, C. (2017a). Stabilisation of track substructure with geo-inclusions - experimental evidence and DEM simulation. International Journal of Rail Transportation.

Ngo, N.T., Indraratna, B. and Rujikiatkamjorn, C. (2017b). A study of the geogrid-subballast interface via experimental evaluation and discrete element modelling. Granular Matter, 19(3), pp: 54: 51-16.

Nimbalkar, S. and Indraratna, B. (2016). Improved performance of ballasted rail track using geosynthetics and rubber shockmat. Journal of Geotechnical and Geoenvironmental Engineering, 142(8), pp: 04016031.

Meyers M.A. (1994). Dynamic Behavior of Materials, John Wiley and Sons, Inc. New York.

Paixão, A., Alves Ribeiro, C., Pinto, N., Fortunato, E. and Calçada, R. (2014). On the use of under sleeper pads in transition zones at railway underpasses: experimental field testing. Structure and Infrastructure Engineering, pp: 1-17.

Powrie, W., Yang, L.A. and Clayton, C.R.I. (2007). Stress changes in the ground below ballasted railway track during train passage. Proceedings of the Institution of Mechanical Engineers: Part F: Journal of Rail and Rapid Transit, pp: 247-261.

Priest, J.A., Powrie, W., Yang, L., Grabe, P.J. and Clayton, I. (2010). Measurements of transient ground movements below a ballasted railway line. Géotechnique, 60(9), pp: 667-677.

Selig, E.T. and Waters, J.M. (1994). Track geotechnology and substructure management, Thomas Telford, London.

Sayeed, M.A. and Shahin, M.A. (2016). Three-dimensional numerical modelling of ballasted railway track foundations for high-speed trains with special reference to critical speed. Transportation Geotechnics, 6, pp: 55-65.

Shukla, S.K. and Yin, J.H. (2006). Fundamentals of Geosynthetic Engineering, Taylor \& Francis Group, London, UK.

Sun, Q., Indraratna, B. and Ngo, N.T. (2018). Effect of increase in load and frequency on the resilience of railway ballast. Géotechnique, DOI: https://doi.org/10.1680/jgeot.17.P.302

Tennakoon, N., Indraratna, B., Rujikiatkamjorn, C., Nimbalkar, S. and Neville, T. (2012). The role of ballast fouling characteristics on the drainage capacity of rail substructure. Geotechnical Testing Journal, 35(4), pp: 1-11.

Tutumluer, E., Huang, H. and Bian, X. (2012). Geogrid-aggregate interlock mechanism investigated through aggregate imaging-based discrete element modeling approach. International Journal of Geomechanics, 12(4), pp: 391-398.

Varandas, J.N., Hölscher, P. and Silva, M.A.G. (2011). Dynamic behaviour of railway tracks on transitions zones. Computers \& Structures, 89(13-14), pp: 1468-1479.

Wettschureck, R. (1997). Measures to reduce structure-borne noise emissions induced by aboveground, open railway lines. Rail Engineering International, Edition, 1, 12-16. 


\section{List of Tables}

608 Table 1. Mechanical characteristics of READS

\begin{tabular}{l|l}
\hline Material properties & Values \\
\hline Thickness, $t(\mathrm{~mm})$ & 10 \\
Area weight, $\mathrm{kg} / \mathrm{m}^{2}$ & 8.23 \\
Tensile strength, $\tau\left(\mathrm{N} / \mathrm{mm}^{2}\right)$ & 0.58 \\
Tensile strain at failure, $\varepsilon_{u l t}(\%)$ & 56 \\
Permeability coefficient, $k(\mathrm{~cm} / \mathrm{sec})$ & $2.5 \times 10^{-4}$ \\
Static bedding modulus, $C_{\text {stat }}\left(\mathrm{N} / \mathrm{mm}^{3}\right)$ & $0.142^{\mathrm{a}}$ \\
Dynamic bedding modulus,$C_{d y n}\left(\mathrm{~N} / \mathrm{mm}^{3}\right)$ & $0.107^{\mathrm{a}}$ \\
\hline
\end{tabular}

609 a DIN (German Institute for Standardization). (2010). "Mechanical vibration—Resilient elements 610 used in railway tracks. Part V: Laboratory test procedures for under-ballast mats.” 45673-5, Berlin. 
614 Table 2. Summary of impact testing program

\begin{tabular}{ccccc}
\hline $\begin{array}{c}\text { Test } \\
\text { no. }\end{array}$ & Test name & $\begin{array}{c}\text { Subgrade } \\
\text { condition }\end{array}$ & $\begin{array}{c}\text { READS } \\
\text { used }\end{array}$ & Drop height, $h_{d}(\mathrm{~mm})$ \\
\hline 1 & SY100 & Soft & Yes & 100 \\
2 & SN100 & Soft & No & 100 \\
3 & CY100 & Concrete & Yes & 100 \\
4 & CN100 & Concrete & No & 100 \\
5 & SY150 & Soft & Yes & 150 \\
6 & SN150 & Soft & No & 150 \\
7 & CY150 & Concrete & Yes & 150 \\
8 & CN150 & Concrete & No & 150 \\
9 & SY200 & Soft & Yes & 200 \\
10 & SN200 & Soft & No & 200 \\
11 & CY200 & Concrete & Yes & 200 \\
12 & CN200 & Concrete & No & 200 \\
13 & SY250 & Soft & Yes & 250 \\
14 & SN250 & Soft & No & 250 \\
15 & CY250 & Concrete & Yes & 250 \\
16 & CN250 & Concrete & No & 250 \\
\hline
\end{tabular}

Notation of the test name - for example SY100: $\mathrm{S}=$ soft subgrade $(\mathrm{C}=$ Concrete $/$ stiff subgrade); Y = with recycled rubber mat; drop height, $h_{d}$ 

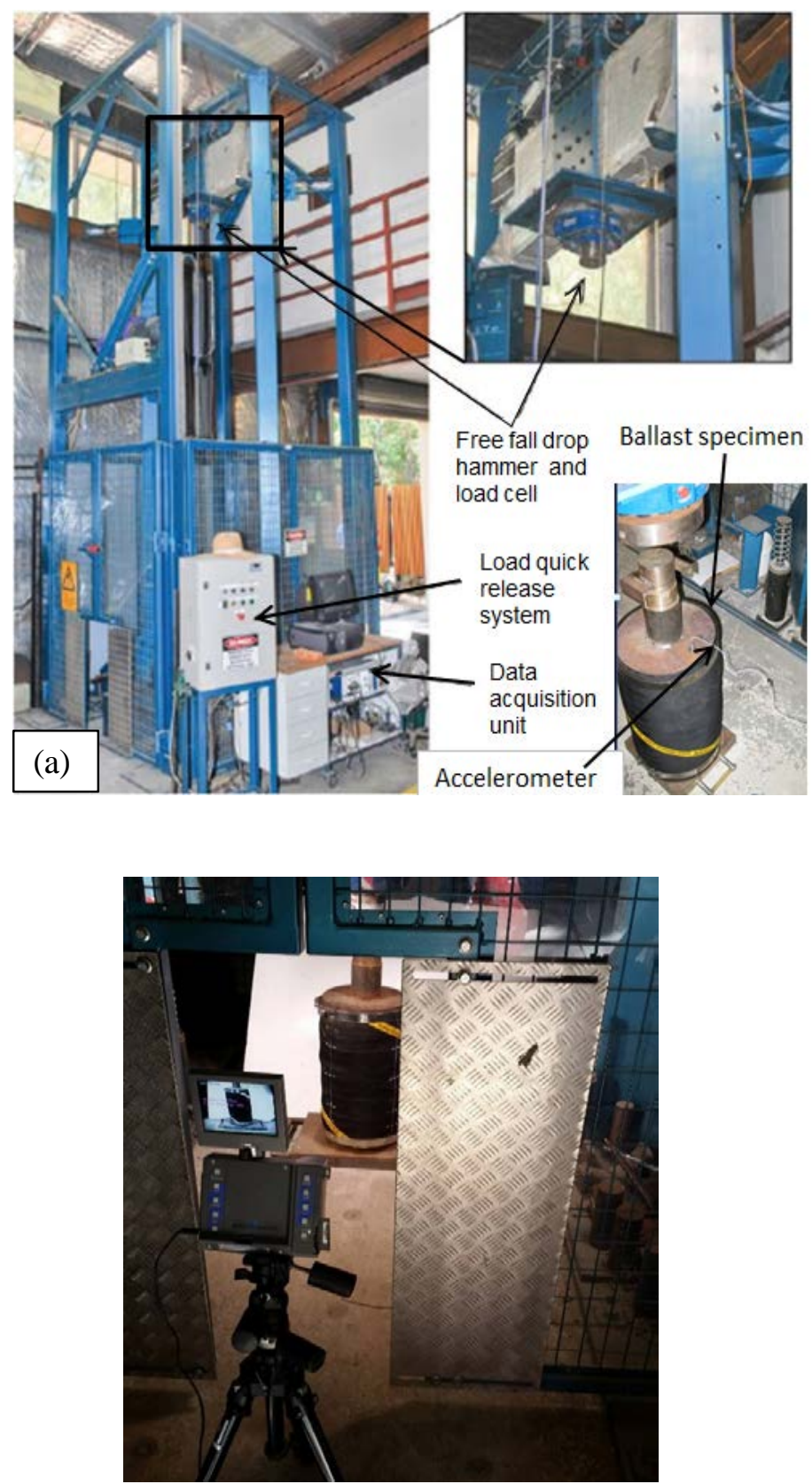

618 (c)

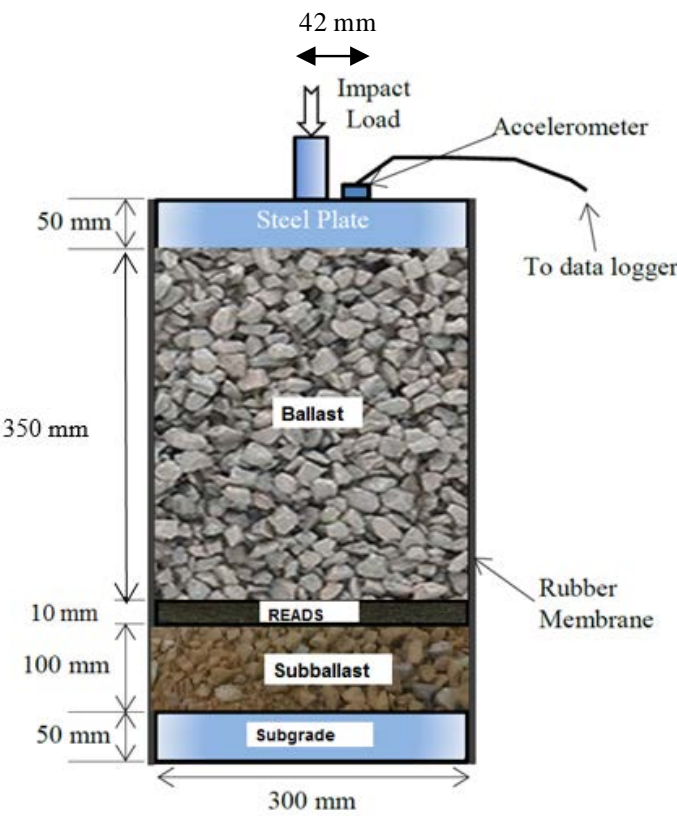

(b)

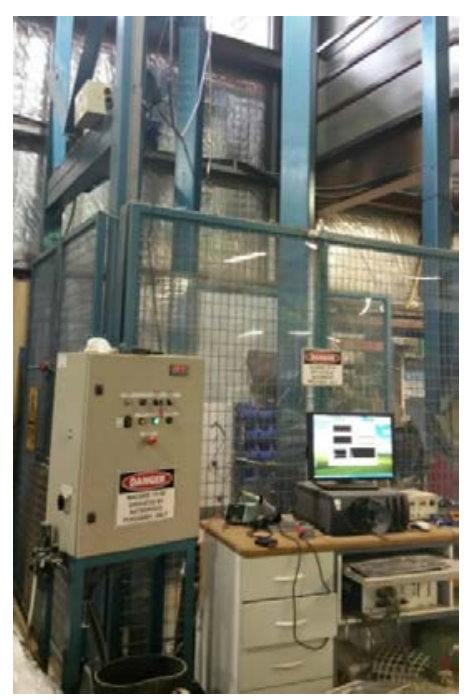

(d)

619 Figure 1. (a) High capacity drop weight impact apparatus; (b) Schematic diagram of ballast sample; 620 (c) High speed camera set up; and (d) Data acquisition unit 


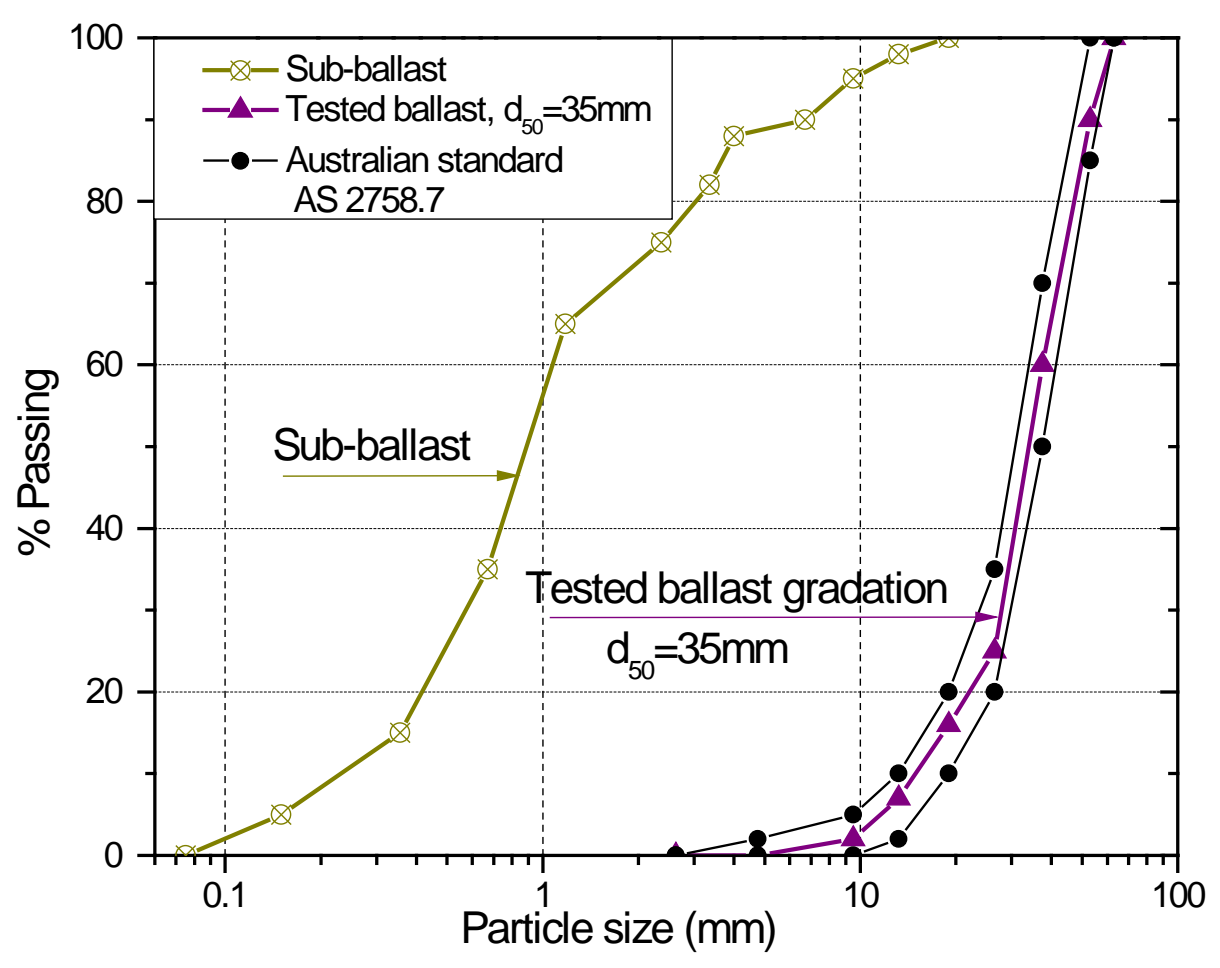

623

624 Figure 2. Particle size distributions of the ballast and capping used in the study

625 


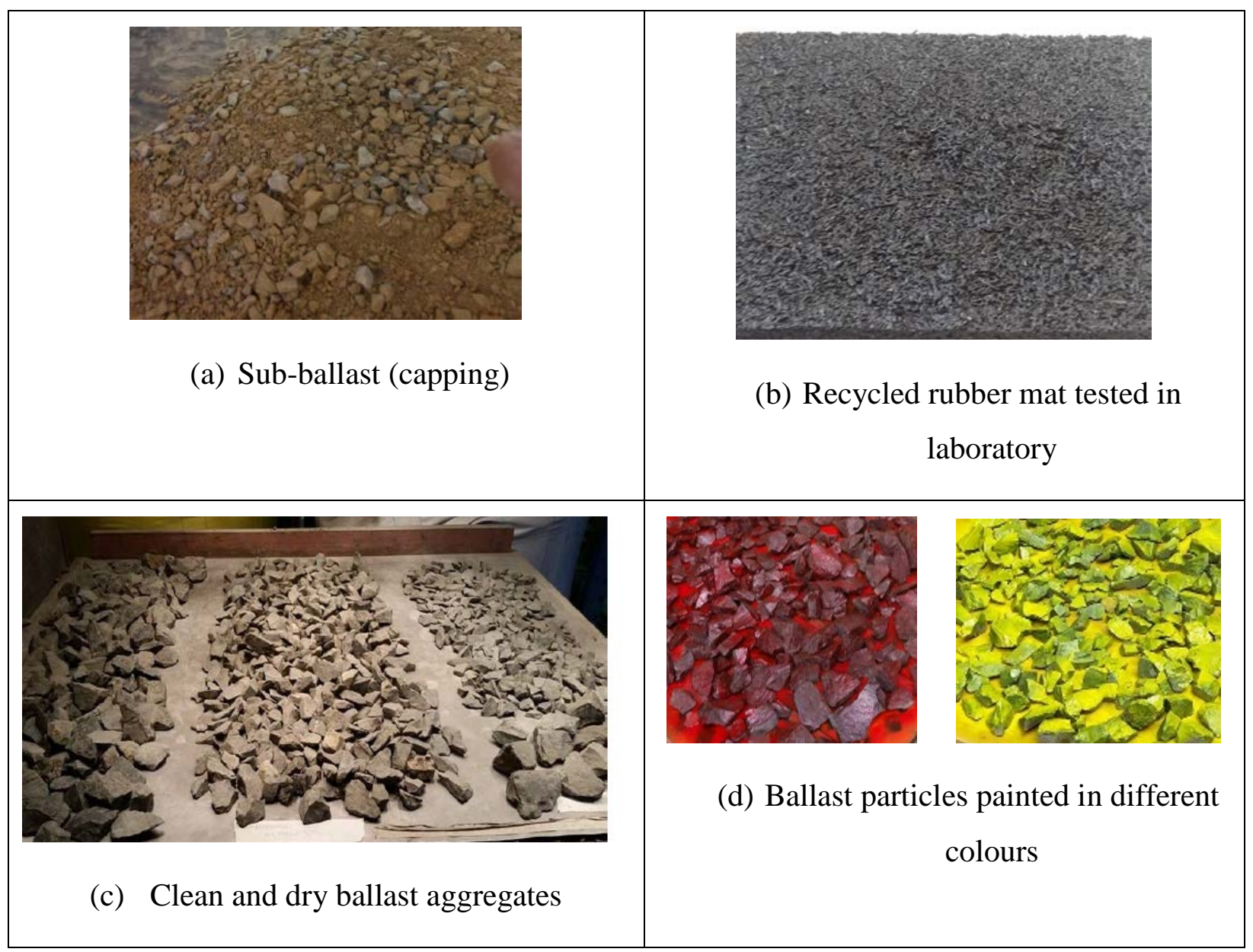

626 Figure 3. Typical images of capping, ballast particles and recycled rubber mat (READS) used in 627 the laboratory

628 


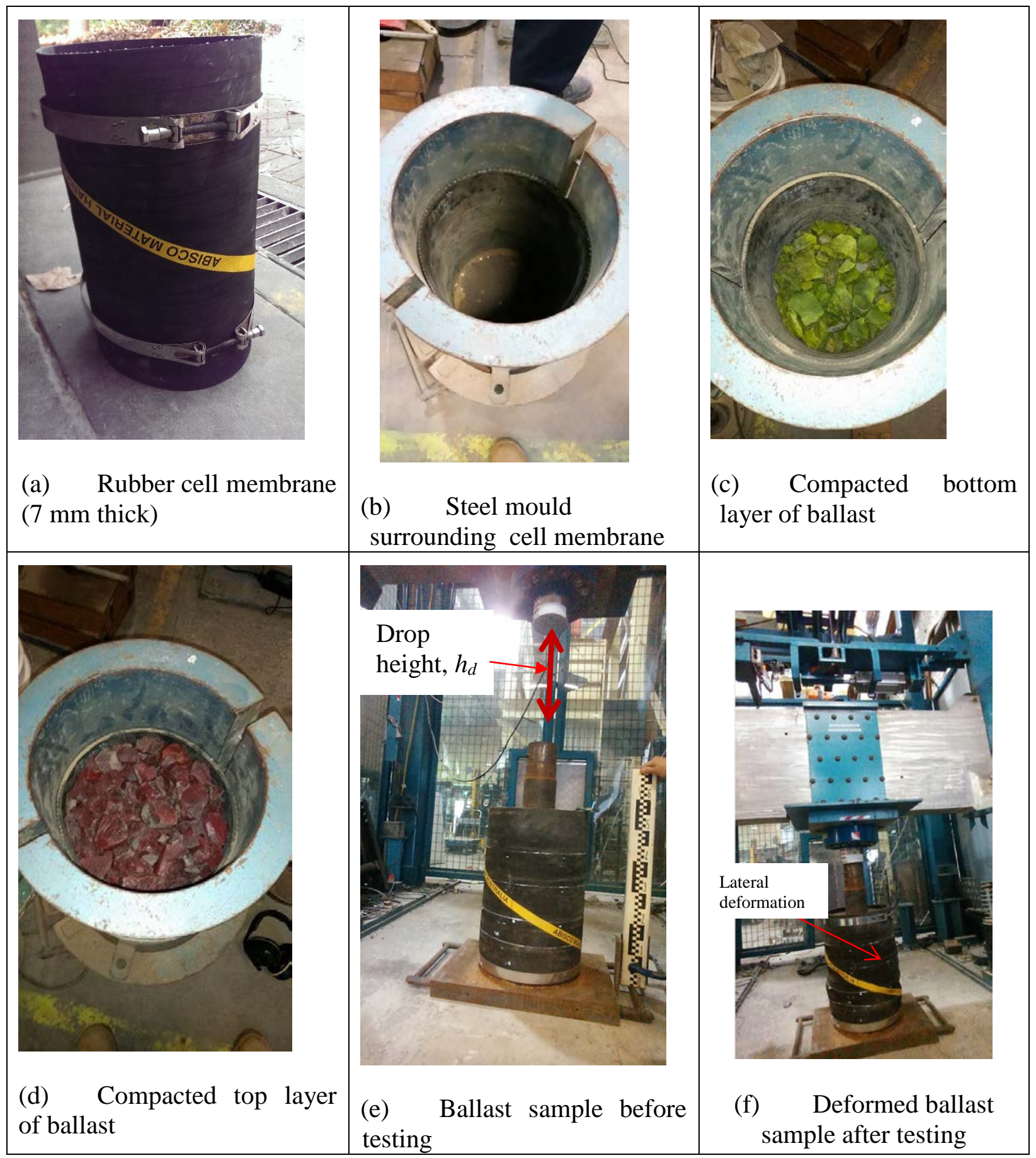

629 Figure 4. Sample preparation: (a) cell membrane; (b) steel mould, (c) ballast at bottom layer; (c)

630 ballast on top layer; (d) ballast specimen; and (f) deformed shape of ballast specimen 


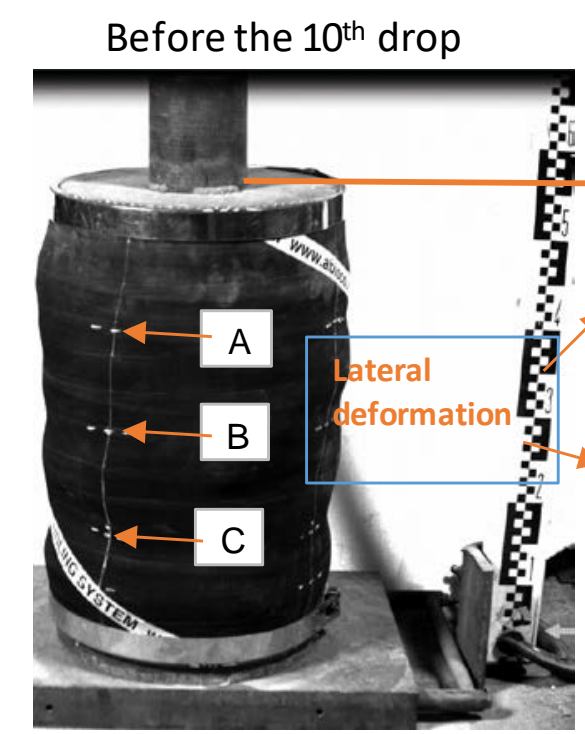

(a) $t=0$

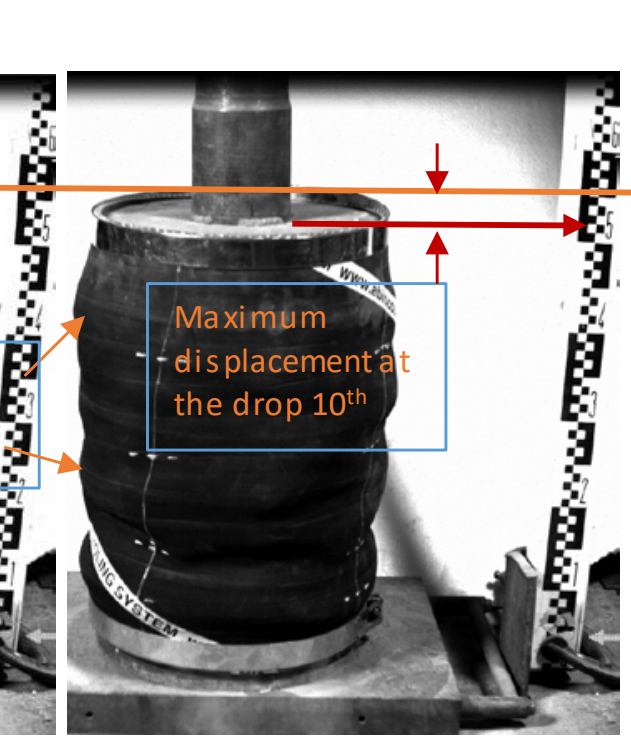

(b) $t=15 \mathrm{~ms}$
After the $10^{\text {th }}$ drop

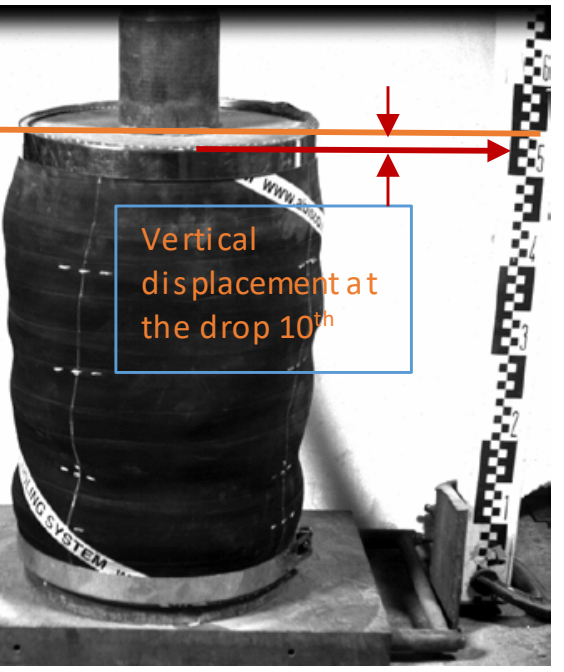

(c) $t=200 \mathrm{~ms}$

Figure 5. Typical images of the deformed ballast assembly recorded before and after the $10^{\text {th }}$ 633 drop, taken by the high-speed camera

634 

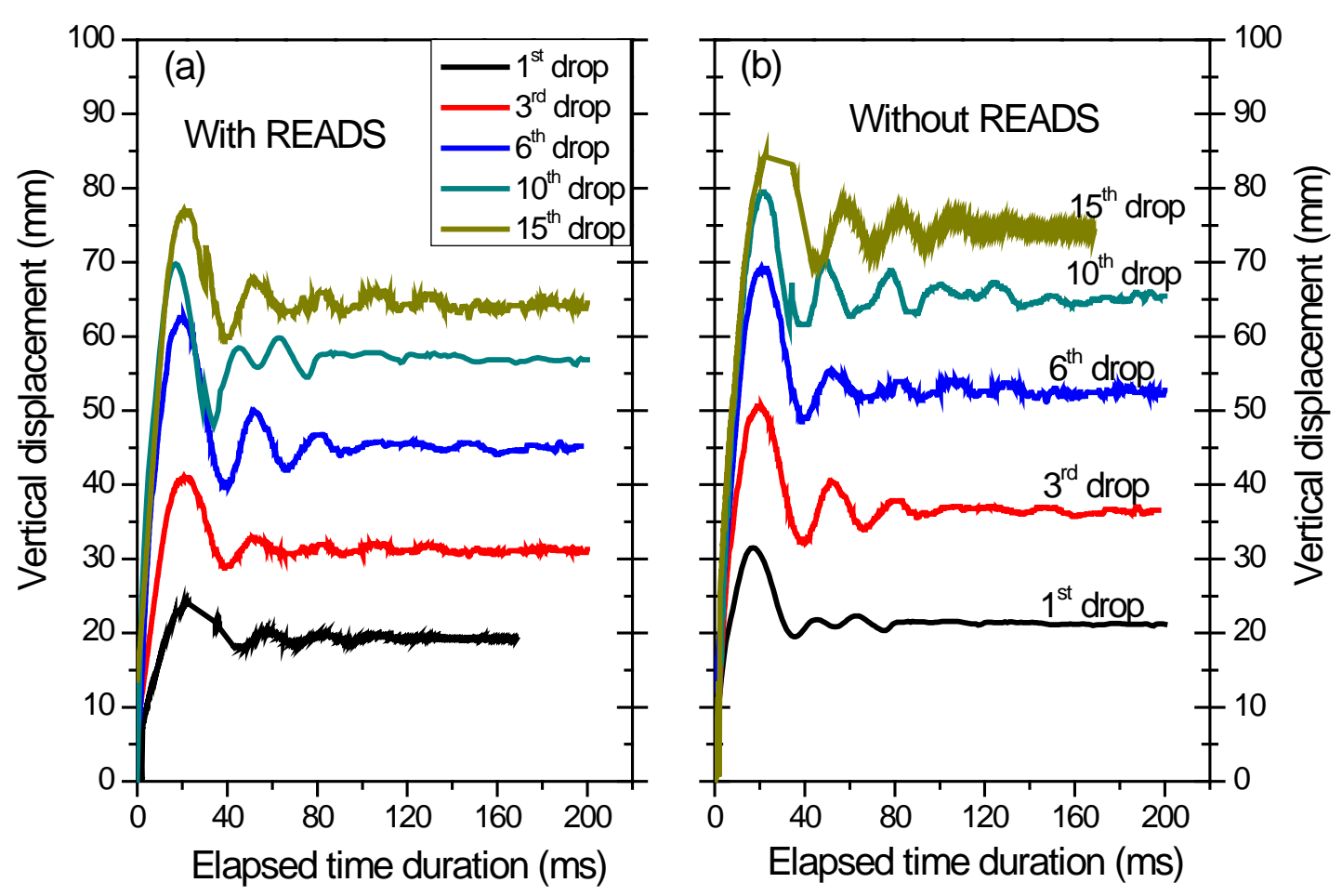

636

637 Figure 6. Measured vertical displacement of ballast assemblies at different drops placed over stiff 638 subgrade: (a) with READS; (b) without READS 


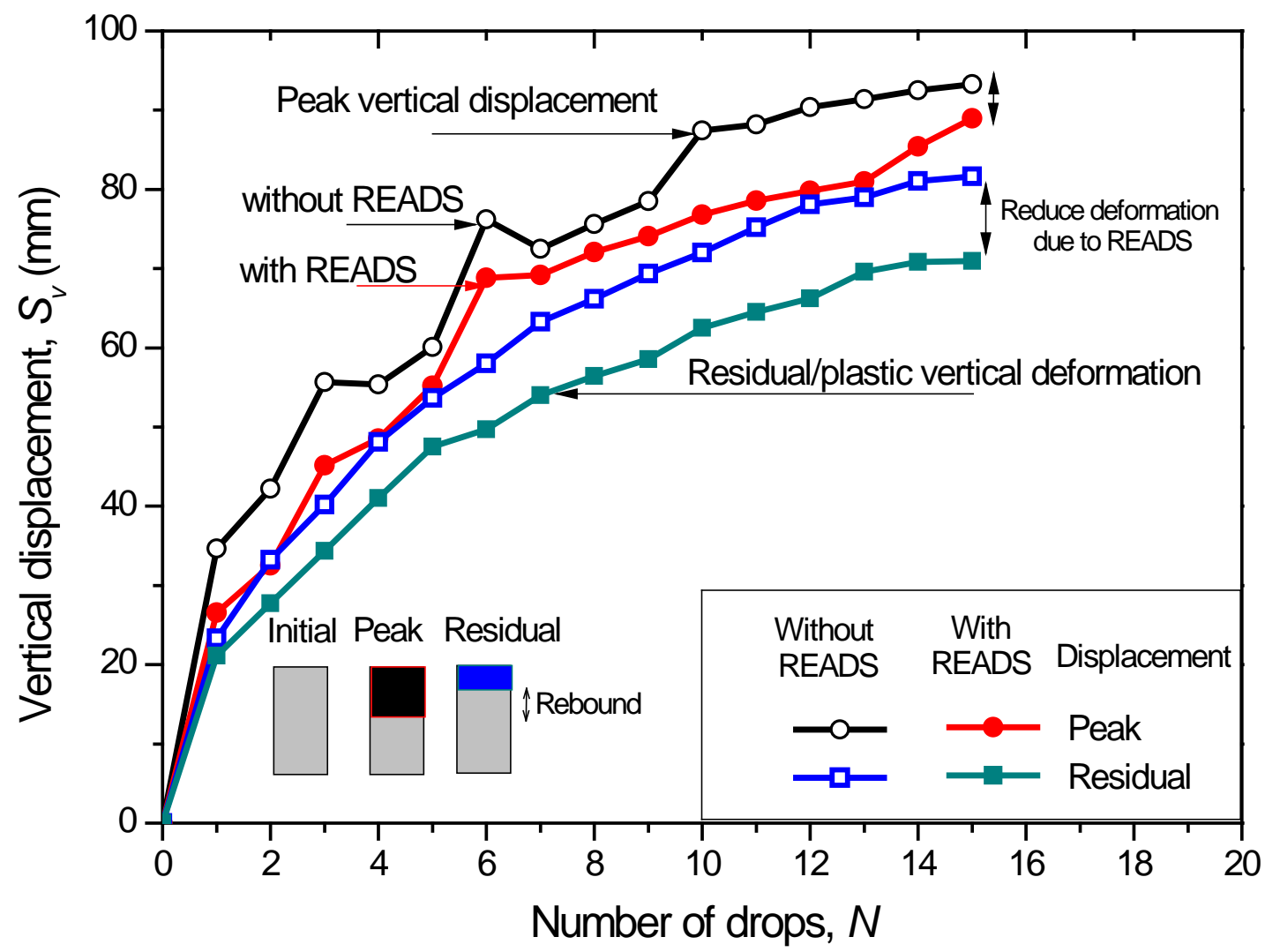

Figure 7. Variation of the peak and residual (permanent) vertical displacement of ballast 644 assemblies with the number of drops 

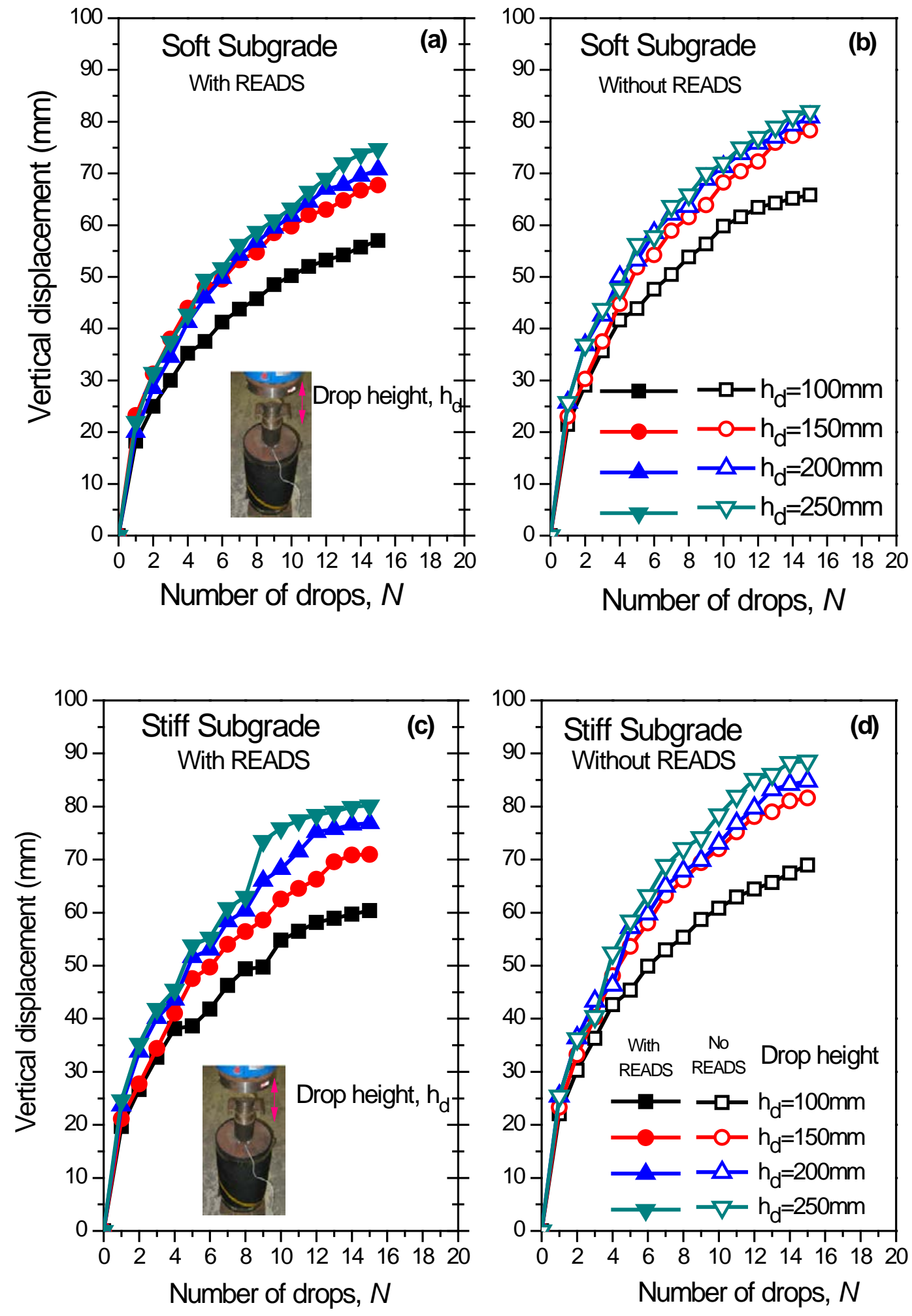

Figure 8. Accumulated permanent vertical settlement of ballast with and without READS: (a)-(b) soft subgrade; (c)-(d): stiff (concrete) base 

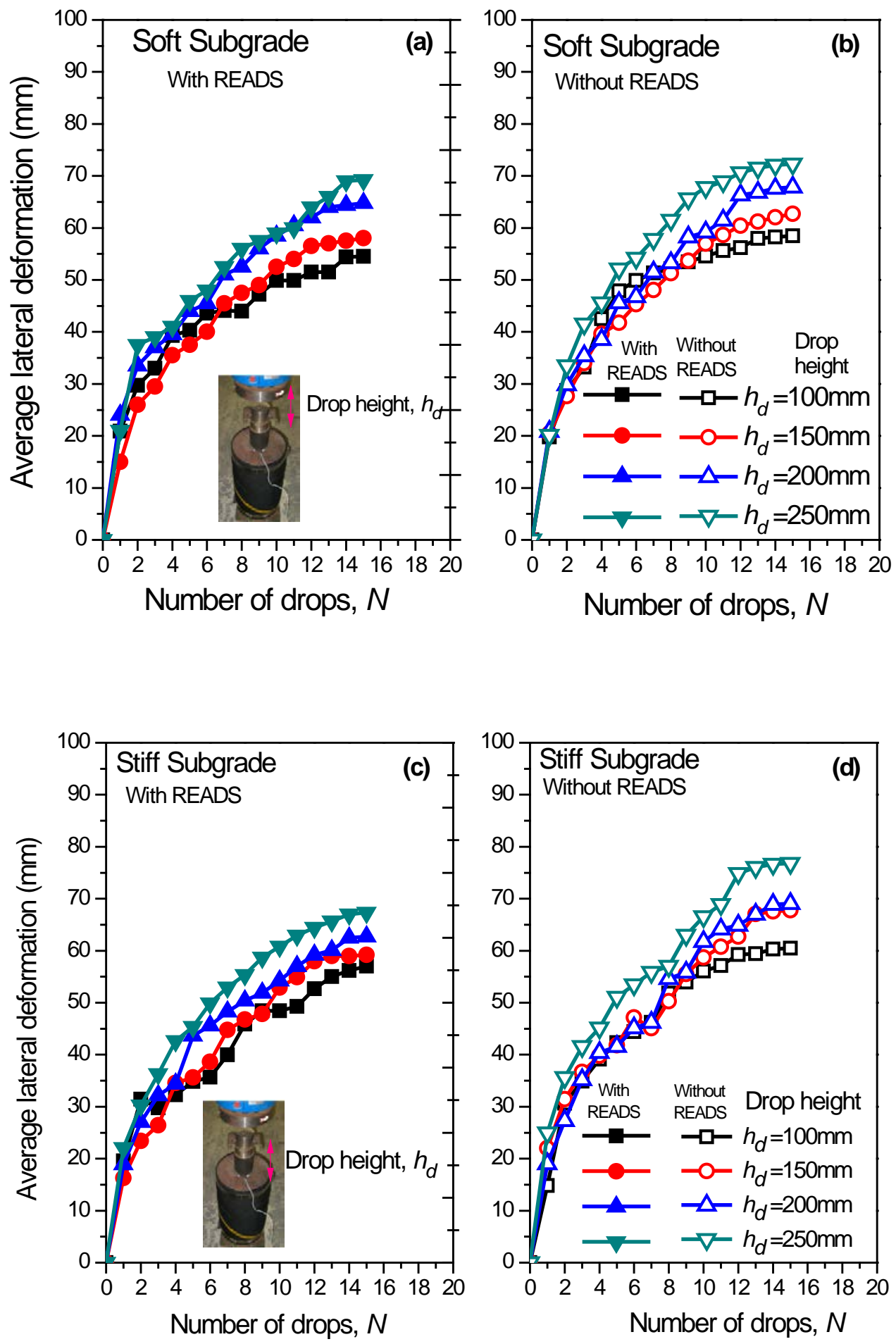

661 Figure 9. Average lateral displacement of ballast with and without READS: (a)-(b) soft 662 subgrade; (c)-(d): stiff (concrete) base 


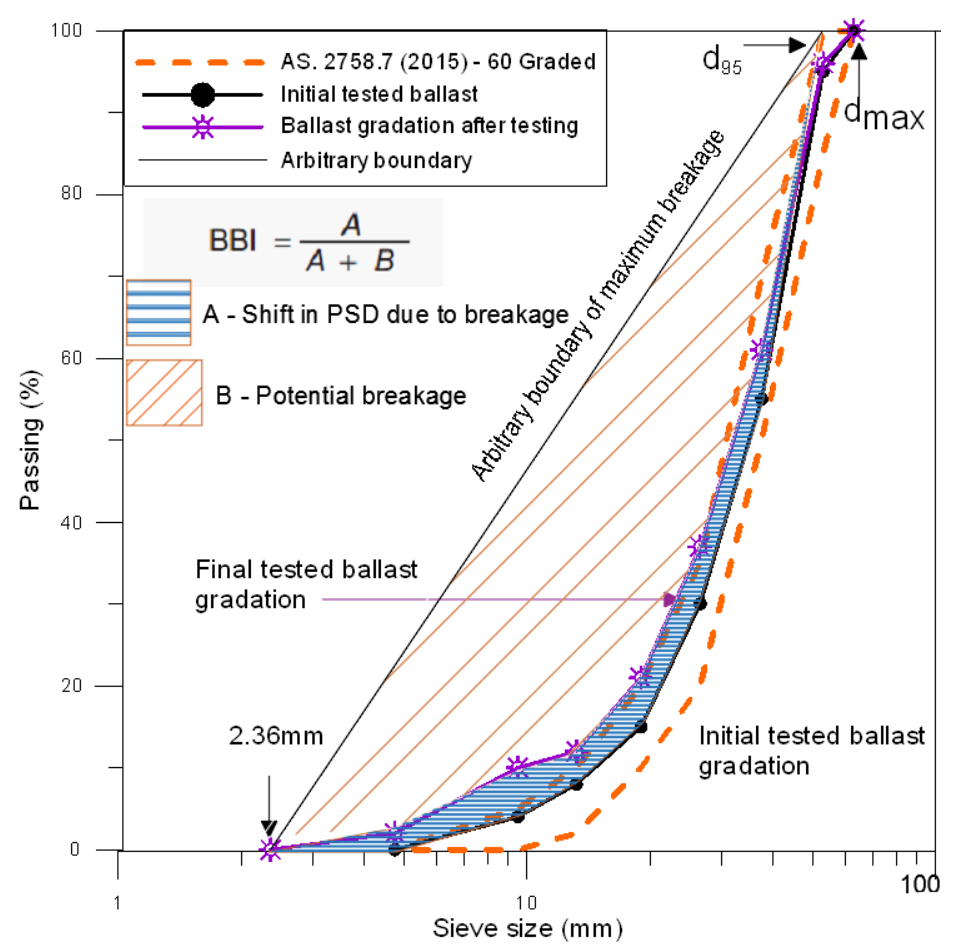

665 Figure 10. Quantification of ballast breakage using the ballast breakage index, $B B I$

666

667 

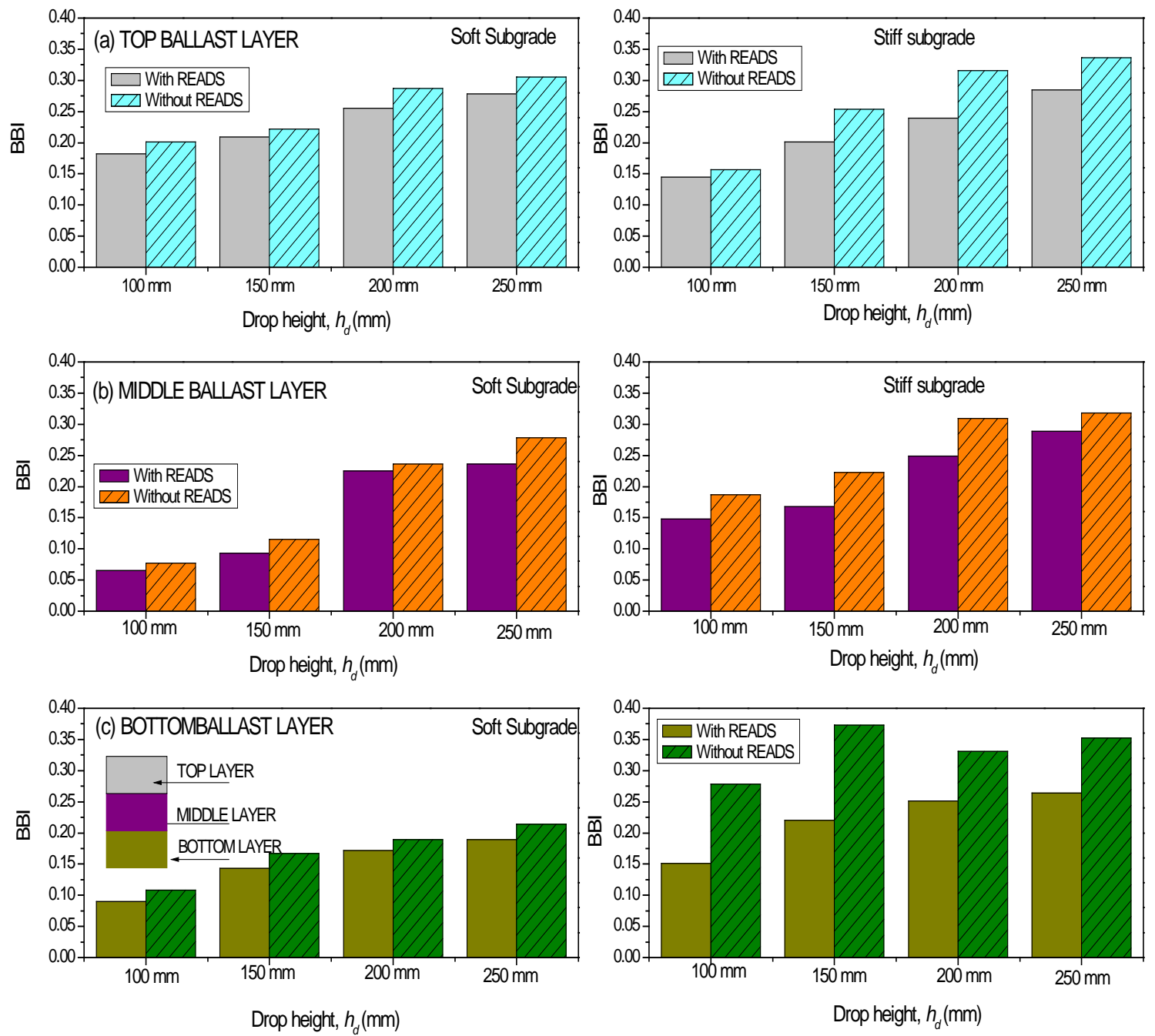

Figure 11. Ballast breakage index (BBI) for soft and stiff subgrades at different ballast layers subject to varying drop heights: (a) top layer; (b) middle layer; and (c) bottom layer 

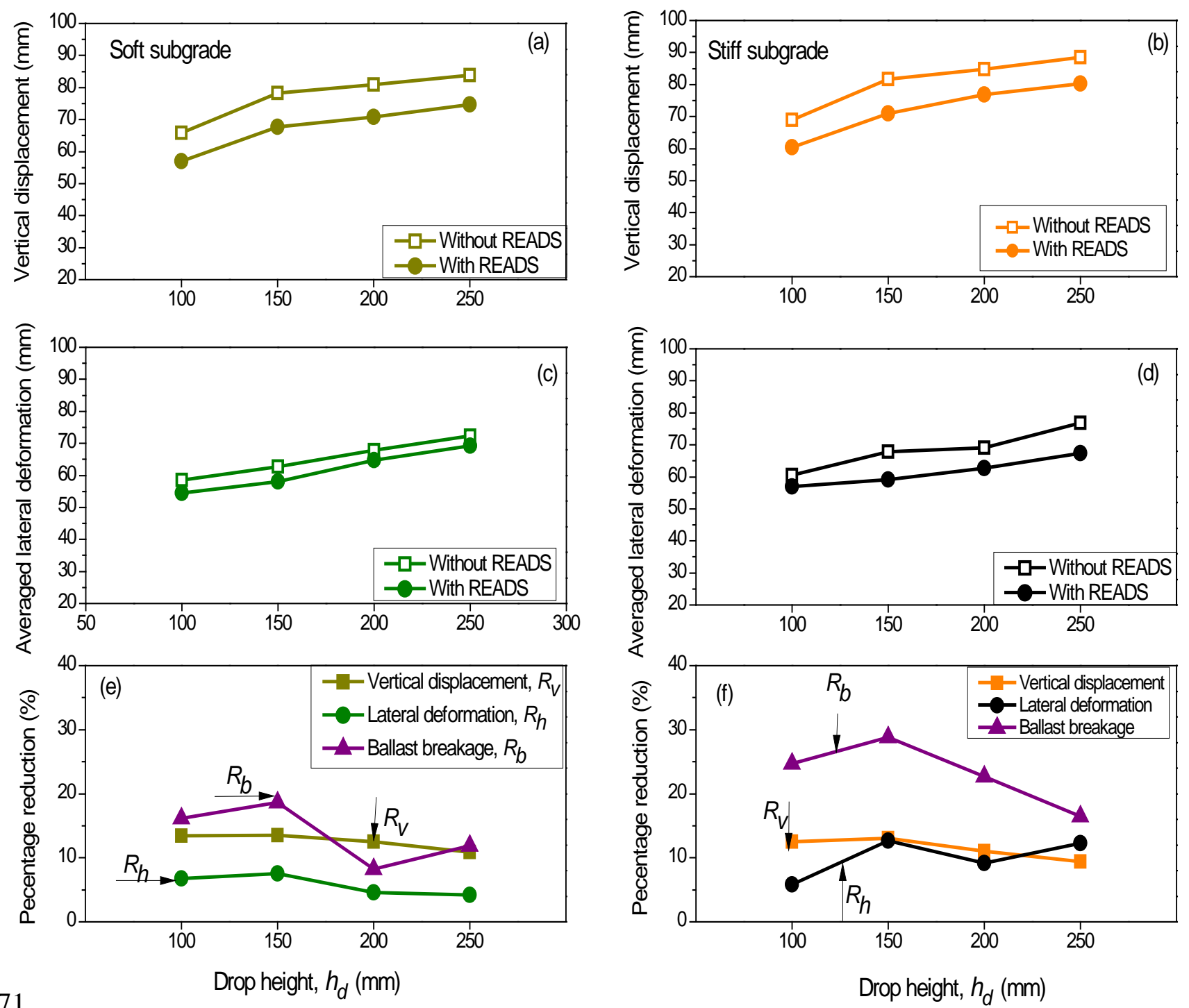

672 Figure 12. Variation of final vertical and lateral deformation of ballast placed on soft and stiff 673 subgrades with and without READS at varied $h_{d}$ : (a-b) vertical displacement; (c-d) lateral 674 displacement; (e-f) percentage reduction of ballast deformation and breakage 

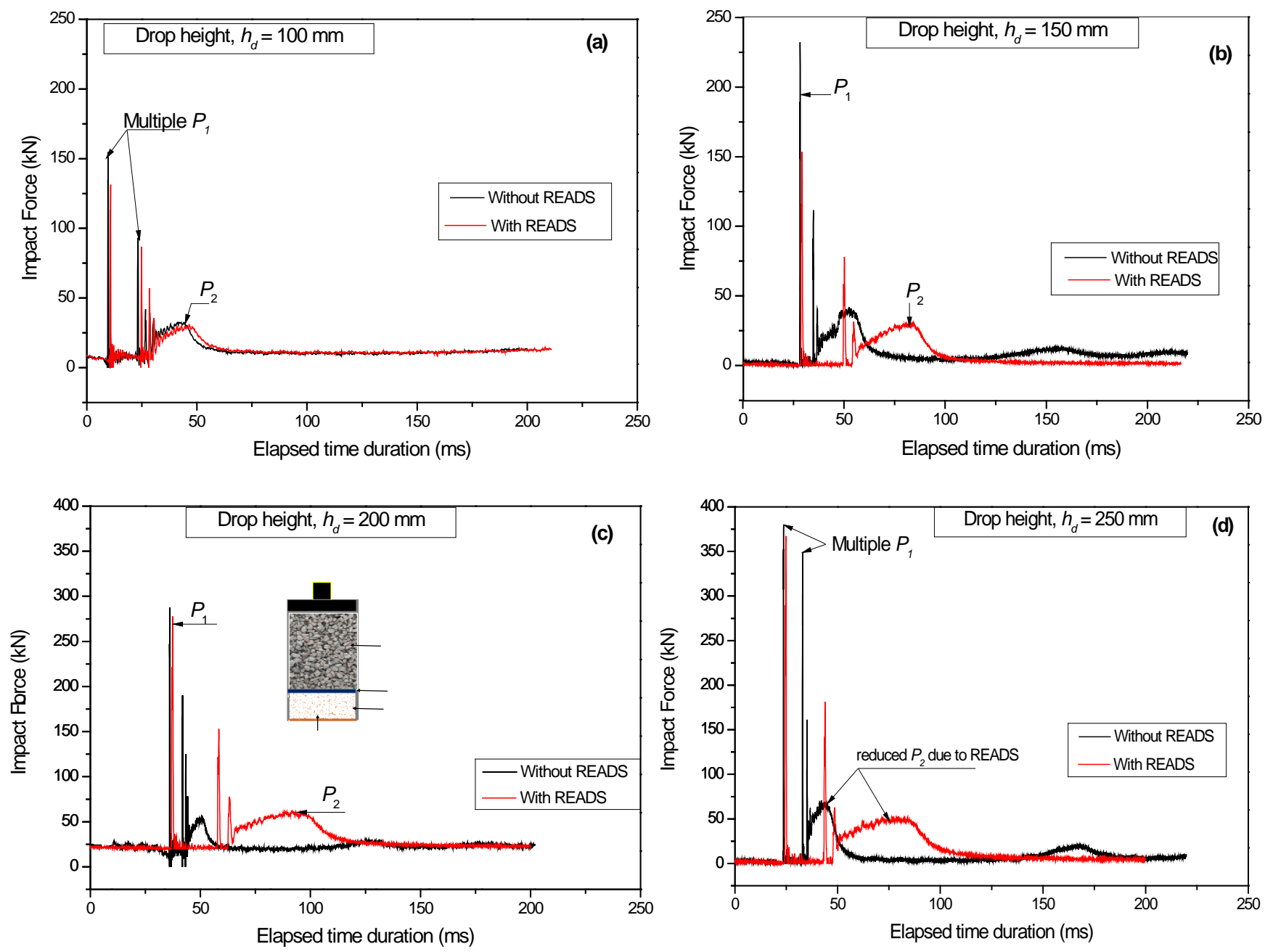

677

678

679

680

Figure 13. Typical impact force responses of ballast with and without READS placed on soft subgrade measured at the drop $N=10$, under varying drop heights: (a) $h_{d}=100 \mathrm{~mm}$; (b) $h_{d}=150$ $\mathrm{mm}$; (c) $h_{d}=200 \mathrm{~mm}$; and (d) $h_{d}=250 \mathrm{~mm}$. 


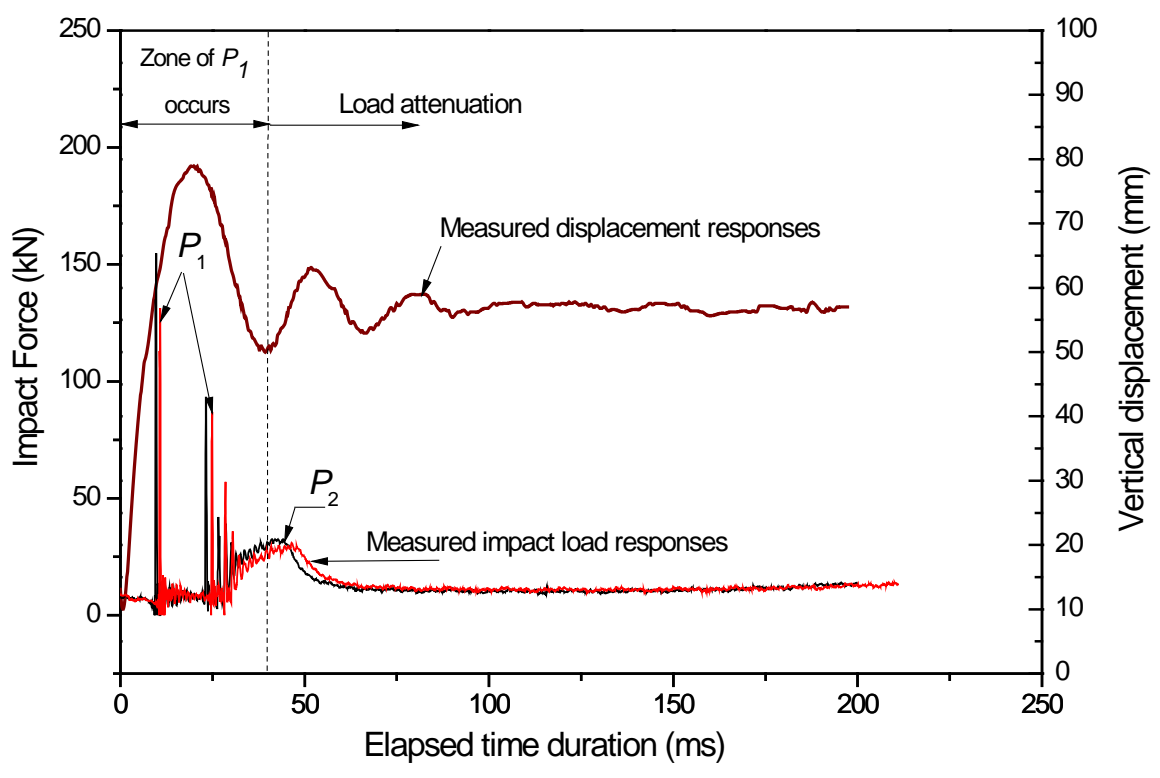

682

683 Figure 14. Measured impact load and vertical displacement of ballast subjected to $h_{d}=100 \mathrm{~mm}$ 684

685 

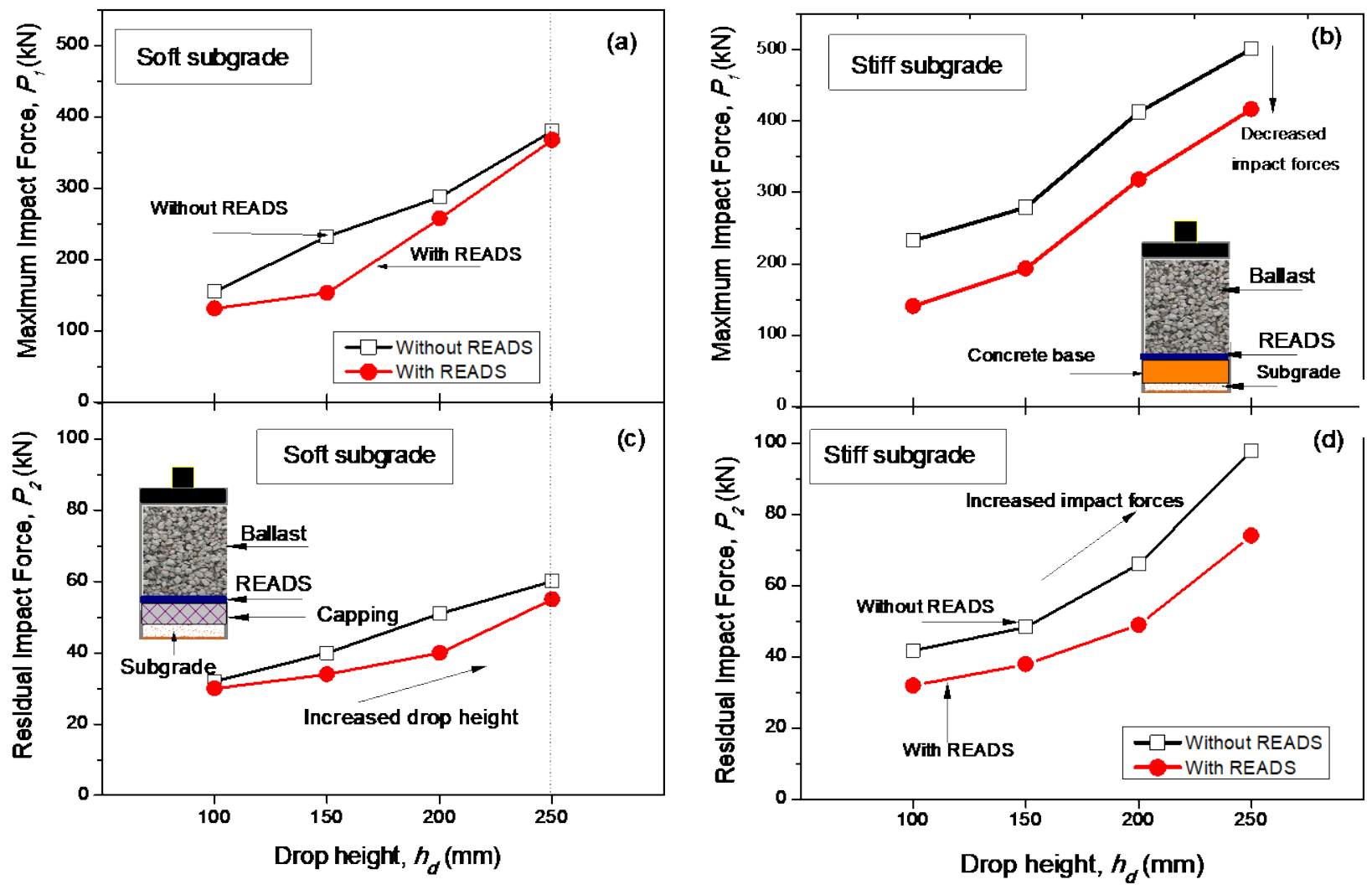

688 Figure 15. Measured impact forces, $P_{1}, P_{2}$ for ballast with and without READS under soft and 689 stiff subgrades after 15 drops ( $N=15$ ): (a) $P_{1}$ - soft subgrade; (b) $P_{1}$ - stiff subgrade; (c) $P_{2}-$ soft 690 subgrade; and (d) $P_{2}$ - stiff subgrade 

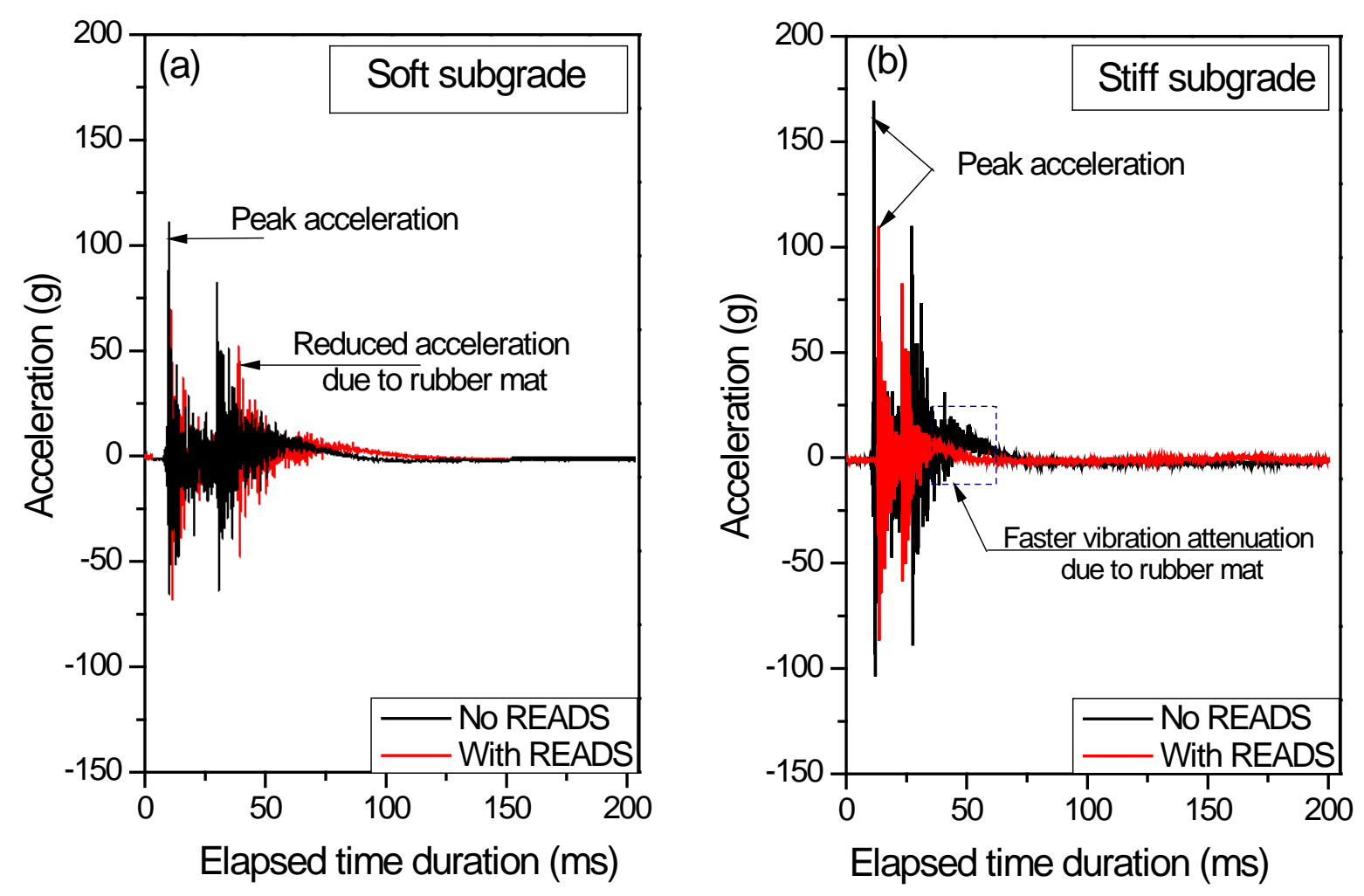

692

693 Figure 16. Measured acceleration of ballast under a drop height of $h_{d}=100 \mathrm{~mm}$, at the $10^{\text {th }}$ drop $694 \quad(N=10)$ placed on: (a) soft subgrade; and (b) stiff subgrade

695

696 


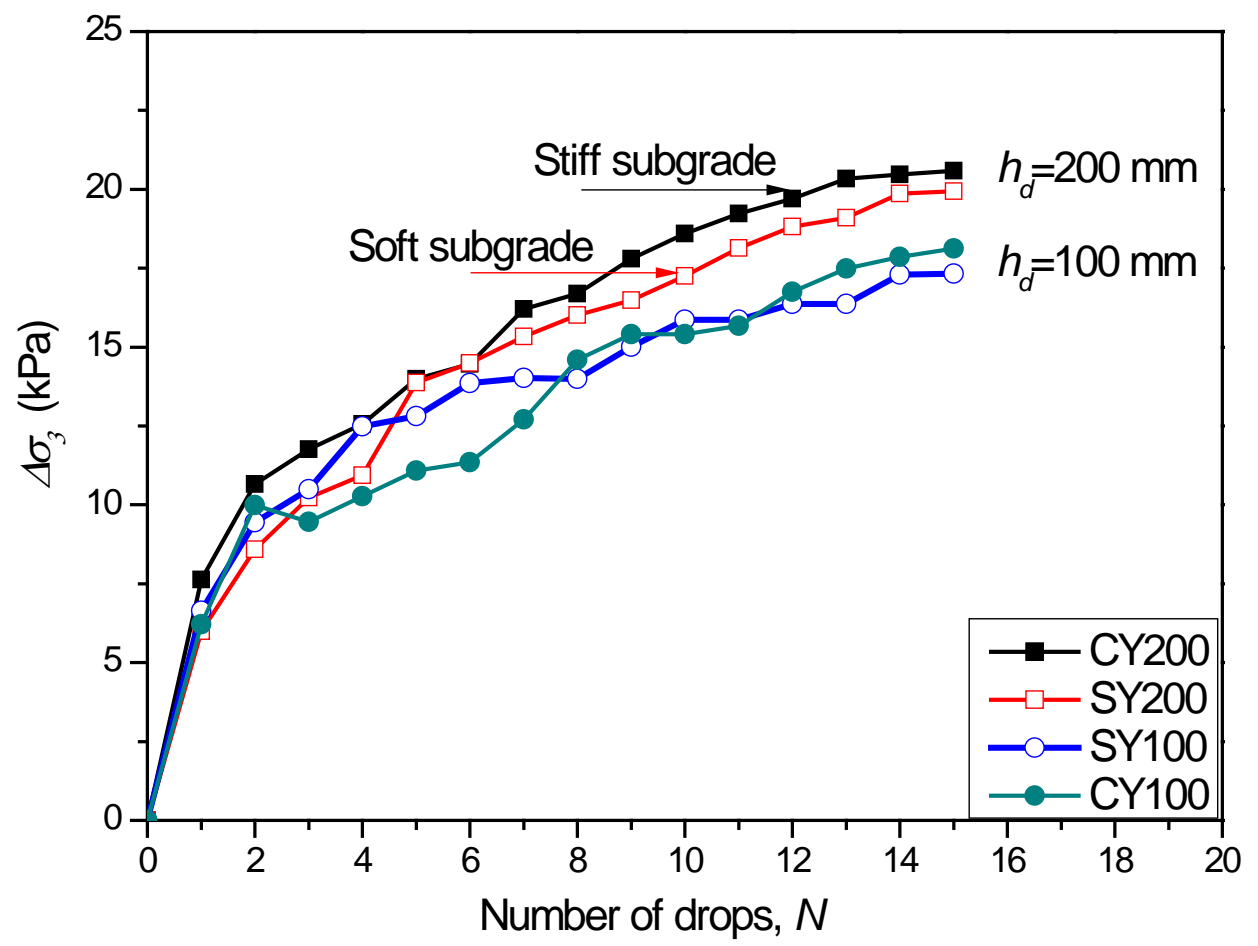




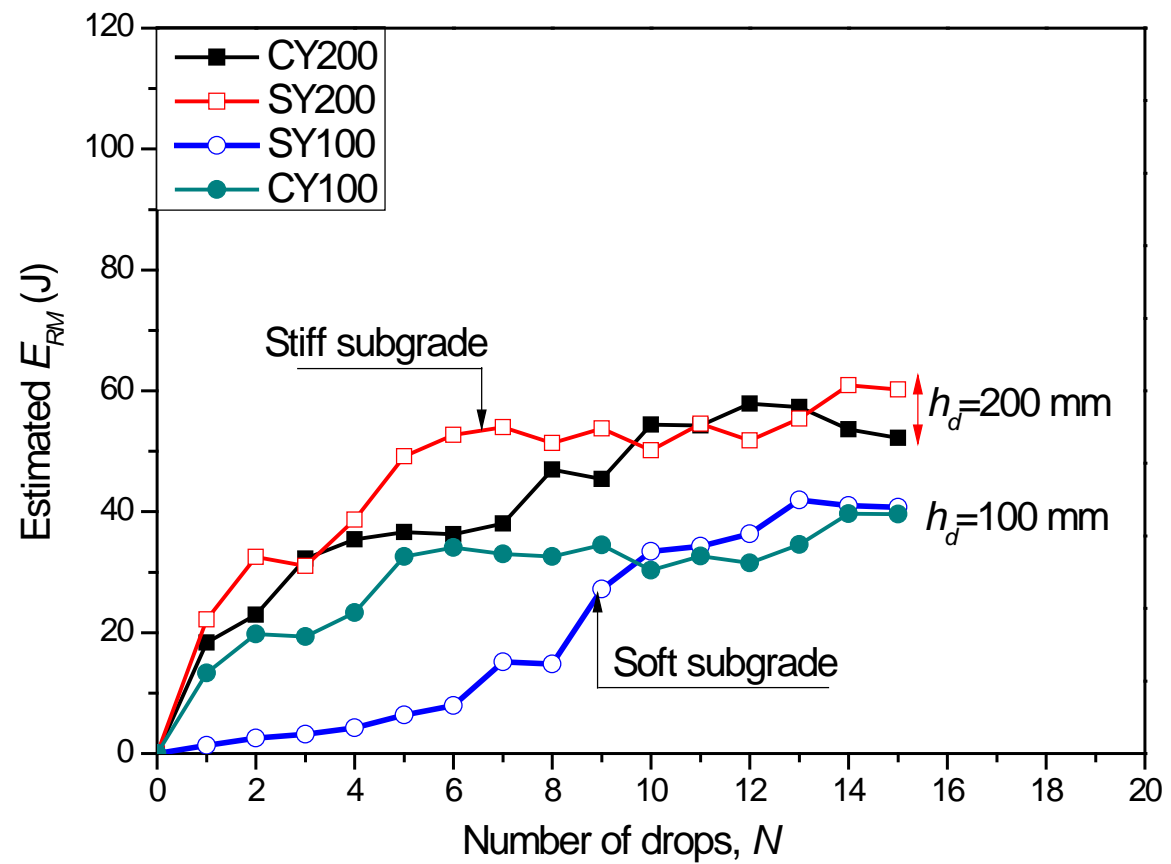

709

710 Figure 18. Estimated energy absorbing of recycled rubber mat $\left(E_{R M}\right)$ that is placed on the soft and 711 stiff subgrade materials 